Florida International University FIU Digital Commons

FIU Electronic Theses and Dissertations

University Graduate School

4-6-2001

\title{
Assessing the construct validity of a measure of learning agility
}

James Connolly

Florida International University

DOI: $10.25148 /$ etd.FI14060893

Follow this and additional works at: https://digitalcommons.fiu.edu/etd

Part of the Psychology Commons

\section{Recommended Citation}

Connolly, James, "Assessing the construct validity of a measure of learning agility" (2001). FIU Electronic Theses and Dissertations. 2424.

https://digitalcommons.fiu.edu/etd/2424

This work is brought to you for free and open access by the University Graduate School at FIU Digital Commons. It has been accepted for inclusion in FIU Electronic Theses and Dissertations by an authorized administrator of FIU Digital Commons. For more information, please contact dcc@fiu.edu. 


\title{
FLORIDA INTERNATIONAL UNIVERSITY \\ Miami, Florida
}

\section{ASSESSING THE CONSTRUCT VALIDITY OF A MEASURE OF LEARNING AGILITY}

\begin{abstract}
A dissertation submitted in partial fulfillment of the requirements for the degree of DOCTOR OF PHILOSOPHY in
\end{abstract} PSYCHOLOGY

by James Connolly 
To: Dean Arthur W. Herriott

College of Arts and Sciences

This dissertation, written by James Connolly, and entitled Assessing the Construct Validity of a Measure of Learning Agility, having been approved in respect to style and intellectual content, is referred to you for judgment.

We have read this dissertation and recommend that it be approved.

Juan I. Sanchez

Janat F. Parker

Paul K. Sugrue

Chockalingam Viswesvaran, Major Professor

Date of Defense: April 6, 2001

The dissertation of James Connolly is approved.

Dean Arthur W. Herriott

College of Arts and Science

Dean Douglas Wartzok Division of Graduate Studies

Florida International University, 2001 
(C) Copyright 2001 by James Connolly

All rights reserved. 


\section{DEDICATION}

I dedicate this dissertation to my sister Kathleen, who taught me that with persistence, all things are possible. 


\section{ACKNOWLEDGMENTS}

I thank the members of my committee for their encouragement and guidance: Juan Sanchez, Janat Parker, and Paul Sugrue. I also thank Scott Fraser, who always had time to listen and offer advise. Lastly, I thank my chairperson, and advisor Chockalingam "Vish" Viswesvaran whose leadership and knowledge enabled me to achieve my goals.

I offer special thanks to my friends and colleagues Marie Williams, Guillermo Wated, Eyran Kraus, and Nila Sinha for their support.

I also thank my family: all four parents, grandparents, aunts, my sisters Christine and Kathleen, my brothers John and Drew whose shoulders I stood upon to reach for the heavens.

Most of all I thank my dear wife Michele, who day in and day out for 5 years, endured, encouraged, worked and supported me throughout this adventure! 


\title{
ABSTRACT OF THE DISSERTATION
}

\section{ASSESSING THE CONSTRUCT VALIDITY OF A MEASURE OF}

\author{
LEARNING AGILITY
}

by

James Connolly

Florida International University, 2001

Miami, Florida

Professor Chockalingam Viswesvaran, Major Professor

This study examined the construct validity of the Choices questionnaire that purported to support the theory of Learning Agility. Specifically, Learning Agility attempts to predict an individual's potential performance in new tasks. The construct validity will be measured by examining the convergent/discriminant validity of the Choices Questionnaire against a cognitive ability measure and two personality measures. The Choices Questionnaire did tap a construct that is unique to the cognitive ability and the personality measures, thus suggesting that this measure may have considerable value in personnel selection. This study also examined the relationship of this new measure to job performance and job promotability. Results of this study found that the Choices Questionnaire predicted job performance and job promotability above and beyond cognitive ability and personality. Data from 107 law enforcement officers, along with two of their co-workers and a supervisor resulted in a correlation of .08 between Learning Agility and cognitive ability. Learning Agility correlated .07 with Learning 


\section{ABSTRACT OF THE DISSERTATION}

(continued)

Goal Orientation and .17 with Performance Goal Orientation. Correlations with the Big Five Personality factors ranged from -.06 to .13 with Conscientiousness and Openness to Experience, respectively. Learning Agility correlated .40 with supervisory ratings of job promotability and correlated .37 with supervisory ratings of overall job performance. Hierarchical regression analysis found incremental validity for Learning Agility over cognitive ability and the Big Five factors of personality for supervisory ratings of both promotability and overall job performance. A literature review was completed to intergrate the Learning Agility construct into a nomological net of personnel selection research. Additionally, practical applications and future research directions are discussed. 


\section{TABLE OF CONTENTS}

CHAPTER

PAGE

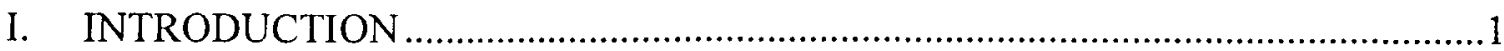

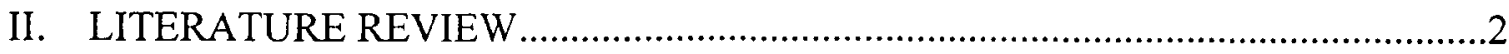

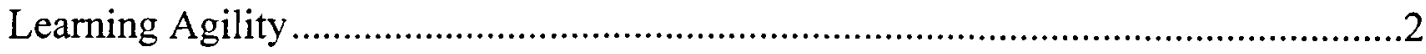

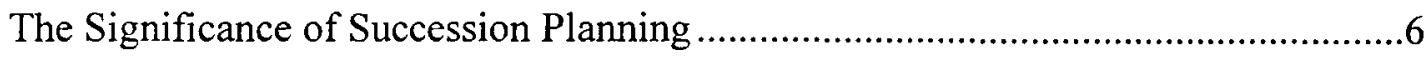

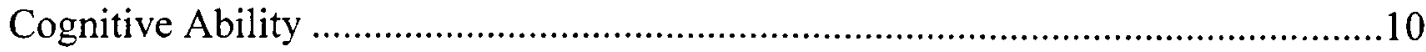

The Relation of Learning Agility to Practical Intelligence.......................................16

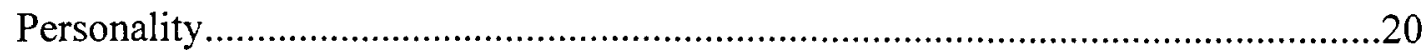

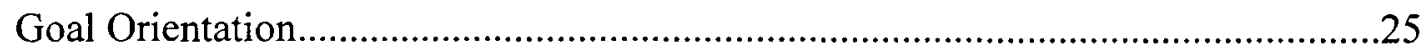

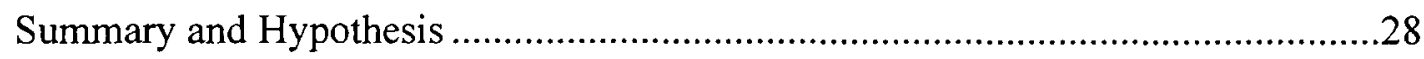

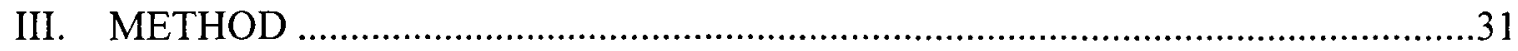

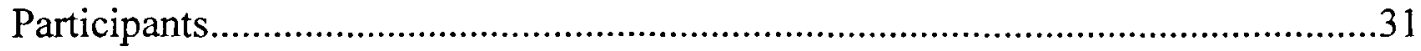

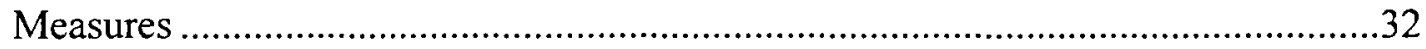

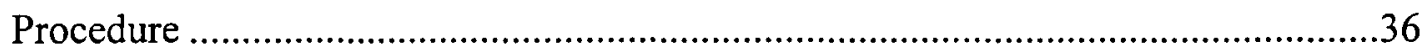

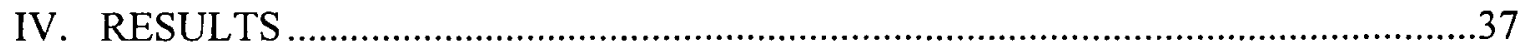

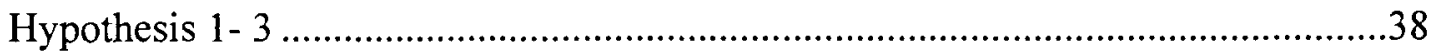

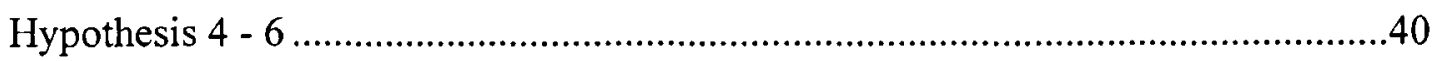

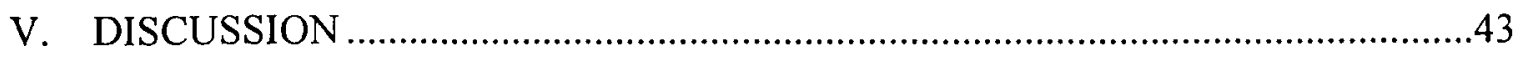

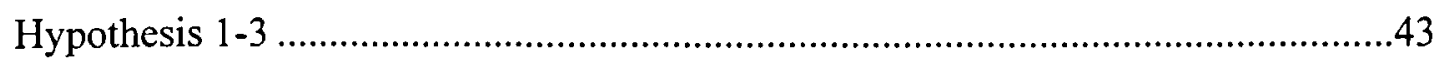

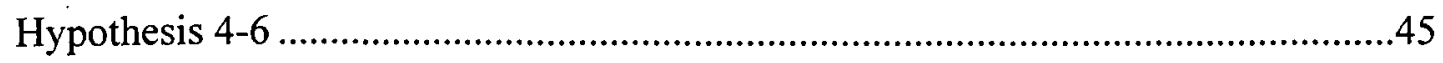

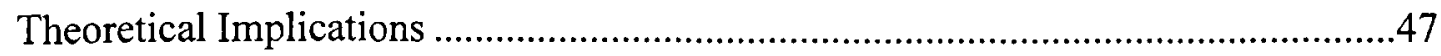

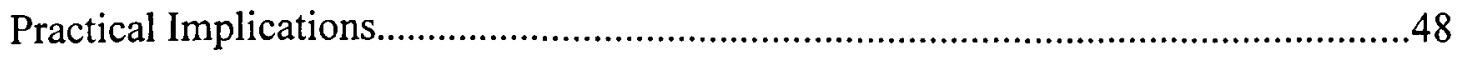


Limitations

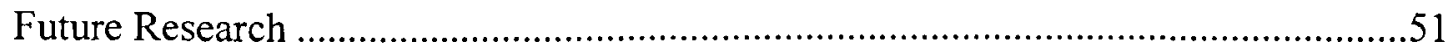

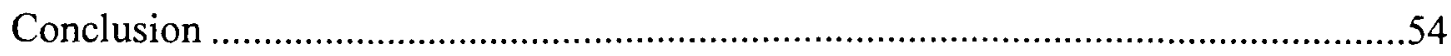

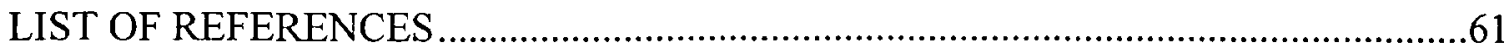

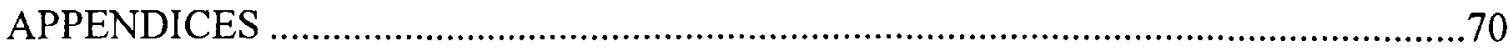

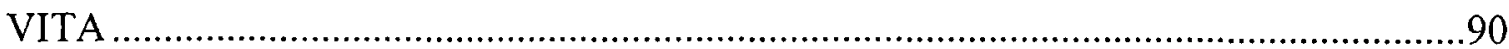




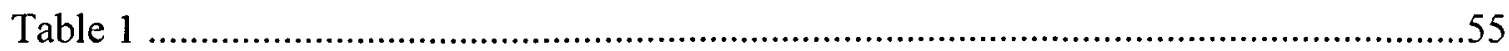

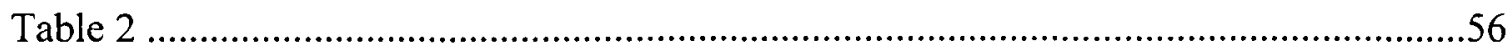

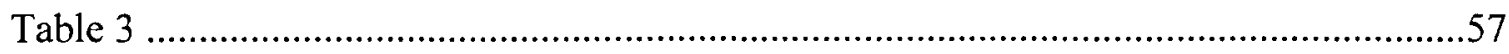

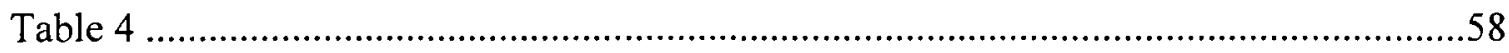

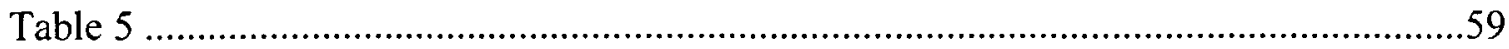

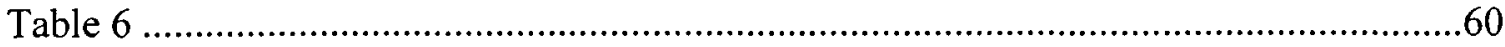




\section{INTRODUCTION}

Cognitive ability (Schmidt \& Hunter, 1998) and personality (Barrick \& Mount, 1991) are two categories of well-established individual difference variables used in personnel selection for predicting job performance. However, the pursuit of finding more valid predictors of job performance is an unending process, with researchers examining variables such as practical intelligence (Sternberg, 1985) and goal orientation (VandeWalle, Brown, Cron, \& Slocum, Jr., 1999) that have been found to predict job performance in addition to the more traditional cognitive ability and personality variables. Recently, researchers have started to examine the individual difference among individuals that differentially enable individuals to learn from their experiences and apply this to excel in new experiences or jobs (Eichinger \& Lombardo, 1997). This study intends to examine the theoretical underpinnings and the construct validity of a measure that purports to predict an individual's ability to learn from his/her experiences and apply this experience to excel in new experiences or jobs by examining the convergent/discriminant validity of the new measure against both a cognitive ability measure and two personality measures. If this new measure taps a construct that is unique compared to the cognitive ability and the two personality measures, then this new measure may have considerable value in personnel selection. This study will also examine the relationship of this new measure to job performance.

Specifically, I will examine the construct and theory assessed by the Choices Questionnaire (Eichinger and Lombardo, 1997) to predict an individual's potential in new jobs. Eichinger and Lombardo (1997) found evidence that this questionnaire predicts job performance/potential $(r=.55)$. Although, Eichinger and Lombardo's (1997) research 
has shown value, more research is needed to examine the construct validity. Results of this study will contribute to the area of research on assessing an individual's potential in new jobs, and may increase our knowledge of how intelligence and personality contribute to job performance.

A literature review of the related constructs will provide a nomological net for this new construct of Learning Agility. First, I will review the literature on Learning Agility, and its application to succession Planning. Next I will review the intelligence literature and the personality literature in relation to Learning Agility. Lastly, I will review goal orientation literature in relation to Learning Agility.

\section{LITERATURE REVIEW}

\section{$\underline{\text { Learning Agility }}$}

Eichinger and Lombardo (1997) have defined learning agility as the willingness and ability to learn new competencies in order to perform for first-time, or under tough or different conditions. One of the selection measures designed to measure learning agility is Eichinger and Lombardo's Choices Questionnaire which is based on their concept of Learning Agility. The Choices Questionnaire is a set of 76 behavior items that is designed to be completed by a rater (i.e., supervisor, co-worker) who knows the person well. The Choices Questionnaire measures Learning Agility, learning from experience, or "Learning II" (to differentiate it from the types of learning that aid in memory, analysis, comprehending new information, or cognitive ability). That is, the questionnaire measures the potential of an individual to learn and perform in new challenging situations. 
The concept of Learning Agility can also be seen in the idea of Adaptive Performance (Pulakos, Arad, Donovan, \& Plamondon, 2000). Pulakos et al., using factor analyses, found that there are 8 factors of adaptive performance and that these 8 factors vary across 21 different types of jobs. These 8 factors include: handling emergencies, handling work stress, solving problems creatively, dealing with uncertain situations, learning, interpersonal adaptability, cultural adaptability, and physically oriented adaptability. Indeed, performing in uncertain and challenging conditions is an important area to examine and understand.

The importance of Learning Agility to personnel selection is also seen in the research conducted by McCall, Lombardo, and Morrison (1988). McCall et al. found successful performers often were better at learning from developmental and challenging assignments. Furthermore, McCall et al. found that certain individuals not only seek out challenging experiences, but they also attempted to find a way to leverage these experiences to further develop their own capabilities. Similarly, McCauley, Ruderman, Ohlott, and Morrow (1994) used developmental experiences as a basis for their Developmental Challenge Profile (DCP). This questionnaire measures job experiences that contribute to management job development. Certainly, this eagerness in certain individuals to extract the most personal beneficial elements from their experiences is a valuable area to examine.

In their two studies, Eichinger and Lombardo (1997) used 423 participants who completed the Choices Questionnaire on someone they knew well. The orthogonal factor analysis of the Choices questionnaire returned four factors that were named: 1) People Agility, 2) Results Agility, 3) Mental Agility, and 4) Change Agility. Eigen values above 
one determined the number of factors, and items loading at or above .40 were retained. 33 items were dropped, and 76 items were retained in the final set. The alpha coefficients range from .86 to .97 for the four factors. Test-retest reliability was reported to range from .81 to .90 (e.g., over a period of 30 days). The factors also correlated significantly with job performance/potential. Eichinger and Lombardo (1997) ran an ANOVA analyses and found that females score higher than males on People Agility, and younger (i.e., $30-39$ age group) individuals scored slightly higher than older individuals (i.e., 40-49 age group). However, the differences in this study between the above two groups (e.g., gender \& age) were small, and the authors conclude that there are no group differences with the scale scores of the Choices Questionnaire.

Eichinger and Lombardo (1997) described the four factors. Mental Agility describes individuals who think through problems from a fresh point of view, are comfortable with complexity, ambiguity and explaining their thinking to others. People Agility describes individuals who know themselves well, learn from experience, treat others constructively, and are cool and resilient under the pressures of change. Results Agility describes people, who get results under tough conditions, inspire others to perform beyond normal, and exhibit the sort of presence that builds confidence in others. Change Agility describes individuals who are comfortable and look forward to experiencing new situations and challenges.

An analysis of the theory of Learning Agility will provide the first step in understanding how this theory is linked to intelligence research. The theory of Learning Agility asserts that individuals who have performed well in the past will not necessarily perform well in the future in a new job. They state that personnel selection should 
combine individual differences that do not change readily and those individual differences that grow as the individual learns to excel at new tasks. One of the keys to being a high potential performer is learning from one's own experience and applying these abilities to excel in new situations. Indeed, potential cannot be detected from a current task the individual excels at, but in new tasks and situations. In Eichinger and Lombardo's definition, potential involves learning new skills (or honing current skills) in order to perform in new or different situations. In general, high learning agile individuals are motivated to learn and are attracted to ideas and people in order to constantly learn.

The theory of Learning Agility is conceptually similar to goal orientation research. Goal orientation has been shown to be a stable individual difference variable made up of two factors: learning goal orientation and performance goal orientation (Button et al., 1996). Learning goal oriented individuals' focus on building new competencies, where performance goal oriented individuals focus on meeting expected standards of competence (e.g., Button et al., 1996; VandeWalle, 1997). Specifically, Change Agility, which is a factor of Learning Agility, is conceptually similar to learning goal orientation. Also, Results Agility, another factor of Learning Agility is also conceptually similar to performance goal orientation.

Eichinger and Lombardo differentiate learning from experience and an individual's intelligence. That is, you cannot predict the ability to learn from experience with intelligence. They also compare learning from experience to street smarts or longterm success in life rather than the ability to process information. Successful individuals are generally superior learners, who extract more benefit from their experiences. Superior learners also excel under new or different situations. In this regard, Learning 
Agile individuals may also be open to or willing to function in new environments. This willingness to experience new situations relates directly to one of the "Big Five" personality dimensions called "openness to Experience". The relationship of Learning Agility to Openness to Experience will be examined later in this paper. Indeed, Learning Agile individuals are substantially better performers and have a greater potential to learn in new situations. Eichinger and Lombardo see the ability to learn consisting of using different learning tactics to gain new competencies.

Learning Agility has several practical applications as well. For example, succession planning systems within organizations are designed to match workers with future job openings. The goal is to identify individuals with high potential, who will excel in new jobs, or individuals who can quickly learn new competencies. Eichinger and Lombardo's (1997) learning agility, which attempts to predict an individual's performance in new jobs, is an important construct for succession planning efforts.

\section{The Significance of Succession Planning}

In today's environment of thin margins, cost cutting, and flatter organizational charts, companies are finding every advantage in order to meet financial expectations for profit and growth. A main cost cutting strategy is doing more work with fewer people, a strategy that has been employed more often recently. This trend has knifed through the management layers as well, thus creating smaller management teams. Smaller management teams have placed an added importance on selecting and promoting management candidates. Finding qualified management candidates in a near zero unemployment rate era and in a growing economy has added to the difficulty in 
management selection. A poorly operating management selection system can have a tremendous negative impact on the organization’s performance (Maccoby, 2000; Pulley, 2000).

Companies also look within for developing management talent (Sloan, 2001), and indeed internal labor markets provide an important source for this management talent. Internal labor markets are characterized by restricted points of entry, career paths, succession planning systems, procedures followed by management, and compensation systems (Pinfield, 1995). Internal labor markets also provide pathways of mobility within the organization, training for employees, increased employee motivation and increased job security (Pinfield, 1995). However, years of flattening the management rank in cost cutting efforts have severely depleted this internal labor market pool of possible management candidates. Nevertheless, organizations are pumping resources into succession planning programs. Succession planning systems work in conjunction with internal compensation models, such as theories of tournament models that pit employees against one another for that next coveted high paying job up the corporate ladder (Becker \& Huselid, 1992; Lambert, Larcker, \& Weigelt, 1993).

Indeed, companies can save money and be more productive if they can promote from within the walls of the organization. An internal management candidate already knows the operational aspects of the company, the culture of the company, is socialized and can quickly, with minimal training, contribute to the profitability of the company. Indeed, an internal candidate for a job saves the organization the initial investment of such socialization techniques as orientation sessions. Clearly the socialization of new hires has important outcomes such as reducing turnover and increasing employee 
productivity (Fisher, 1986; McKenna, 1992). Additionally, another organization effort such as succession planning provides aspiring employees of a career path to see well into the future, thus possibly reducing turnover. Indeed, selecting managers is an important and difficult proposition in today's environment.

Assessing management talent has become an important endeavor for an organization's future prosperity. Organizational selection and succession programs have used many tools in an attempt to assess management talent. Beyond interviewing, organizations may employ a variety of methods for selecting managers. Such methods as the assessment center, cognitive ability measures and personality measures are both widely used and have proven to generate an acceptable amount of validity in predicting job performance (Schmidt \& Hunter, 1998). These methods used in combination represent the most current and effective selection method. However, the search continues to improve the validity of these selection methods.

Succession planning systems examine an individual's past and present performance, but more importantly these systems attempt to determine an individuals possible growth in performance in a new job. Many succession-planning systems assume a strong relationship between current performance and potential performance in a new job. However, the goal is to identify individuals with high potential, who will excel in new jobs, or individuals who can quickly learn new competencies in order to excel. To the extent past and present performance are good indicators of future performance, succession planning based on past and present performance is profitable. Indeed, the use of biodata is predicated on this link. Still, a more direct measure of future performance or Learning Agility would be a useful addition. Assessment centers is one method that 
organizations use to identify bench strength (Chan, 1996), but assessment centers are extremely cost prohibitive. Perhaps another traditional selection system that comes close to assessing individuals for future performance are the "Buddy Nomination" methods. The rationale is to have peers rank candidates on how successful each candidate they will be on the new promoted job (e.g., Mayfield, 1970). Most of the research on Buddy nominations has been conducted in military settings (Hollander, 1965; Williams \& Levitt, 1947). A few studies have explored this possibility in civilian settings. For example, Weitz (1958) found that Buddy Nominations predicted the success of life insurance agents who were promoted to assistant manager positions.

Over the years, given the emphasis on legal issues and the potential for friendship bias in Buddy Nominations (Love, 1981), the use of Buddy Nominations to evaluate future performance of candidates had waned. Moreover, most of the Buddy Nominations systems used in the 1960's and 1970's were unstructured and adhoc. This lack of structure made it more questionable in legal proceedings. However, the logic of Buddy Nominations - the process of asking co-workers to identify individuals who will be successful in the promoted job - is sound. A psychometrically sound structured questionnaire will obviate legal concerns of being consistent to all candidates. Further, rather then asking individuals to assess their coworker's potential job performance on a new job (a requirement that assumes the raters know the performance requirements in the new job), it is more tractable to ask coworkers in a structured format to rate candidates' ability to learn from experiences. Thus, Eichinger and Lombardo's (1997) construct called learning agility, which purports to predict an individual's performance in new jobs, is an important construct for succession planning efforts. 
Learning Agility is a new construct that needs to be connected to a nomological net of traditional predictors. There are numerous individual difference variables used in personnel selection (Murphy, 1996). Among the most researched individual difference variables are cognitive ability and noncognitive ability predictors such as personality and goal orientation. Therefore, a nomological net for Learning Agility should be built around them. Before developing actual predictions, I will review the literature on cognitive ability, personality, followed by a review of the research on goal orientation.

$\underline{\text { Cognitive Ability }}$

Neisser et al. (1996) describes intelligence as individual differences in comprehending difficult concepts, adapting to one's environment, learning from one's experience and surmounting challenges by applying reason. Neisser et al. (1996) asserts that in the field of intelligence, no single theory dominates. Theories on intelligence are varied (Sternberg \& Detterman, 1986). Some theories concentrate on the variance of abilities in relation to $\mathrm{g}$, or they concentrate on $\mathrm{g}$ with a set of partially independent factors, or they support a hierarchical arrangement with $g$ at the apex with specific abilities arrayed underneath. Theories of intelligence are also frequently viewed along two main positions: those who support one unilinear construct of general intelligence $(\mathrm{g})$, and those who support a number of different intelligences.

Ample research exists that supports general mental ability as the best predictor of future job performance and learning (Hunter \& Hunter, 1984; Ree \& Earles, 1992; Ree, Earles \& Teachout, 1994; Schmidt \& Hunter, 1998). General mental ability is also the strongest predictor of the acquisition of job knowledge (Schmidt \& Hunter, 1992; 
Schmidt \& Hunter, 1998) and on performance in job related training programs (Hunter, 1986). For example, Ree, Carretta, and Teachout (1995) found that g indirectly influenced work-sample performance via prior job knowledge and job knowledge obtained in training, and g led directly to the acquisition of Job knowledge.

Researchers past and present who support one general factor of intelligence include Francis Galton (1822-1911), Charles Spearman (1863-1945), Eysenck (1998), and Jensen (1980). Jensen supports Spearman's theory of general intelligence and claims that the correlation of intelligence tests is not an artifact, but a reality of nature (Jensen, 1980). Indeed, the psychometric approach is a well-entrenched methodology supporting the general intelligence theory (Carroll, 1993). Galton's research on reaction times supports the one general mental ability theory of intelligence and according to Galton this intelligence has a biological basis. Spearman researched intelligence using different tests. Spearman found that these intelligence tests correlated positively with each other, and he termed this "positive manifold". This positive manifold supports a robust first factor called general intelligence or $\mathrm{g}$.

Researchers have also conceived of intelligence as consisting of specific abilities. Thurstone (1938) supported his theory of intelligence called "primary mental abilities". These included verbal meaning, perceptual speed, reasoning, number facility, rote memory, word fluency, and spatial relations. Thurstone found his primary mental abilities to be correlated and he later asserted that all cognitive tests must partially contain g. Based on extensive factor analytic research Guilford $(1967,1988)$ has developed the structure -of-intellect (SI) model. This model classifies intellectual traits into three dimensions, termed "Operations", Contents", and "Products". These three dimensions 
make up 180 cells with at least one factor or ability in each cell. However, recent evidence suggests that other models beside the SI model fit the data better (Carroll, 1993).

The Spearman-Thurstone agreement on a hierarchical model, with special abilities correlating together to give support for a factor of general intelligence, is widely supported and there is no real alternative with the similar amount of supporting empirical evidence (Eysenck, 1998; Jensen, 1986).

Cattell's (1887) view of intelligence consisted of two factors: "fluid intelligence" and "crystallized intelligence". The abilities that consist of fluid intelligence are nonverbal, culture-free, and independent of instruction. Crystallized intelligence includes acquired competencies that depend on an exposure to a particular culture as well as formal and informal education. Retrieval of information and application of general knowledge are part of crystallized intelligence. Cattell's theory of intelligence asserts that crystallized intelligence develops through the use of fluid intelligence and that the two are related.

However, a weakness of traditional factor analysis in intelligence research comes from the lack of attention given to the choice of variables to be factor analyzed (Carroll, 1998). Factors identified by factor analysis are taken from the intercorrelations among chosen variables, and most studies of intelligence began with tests designed to measure academic performance (Anastasi \& Urbina, 1997, Carroll, 1998). In order to examine intelligence in broader contexts, however, researchers need to look at individual performance in real-life, culturally valued activities (Anastasi \& Urbina, 1997; Carroll, 1998). 
Furthermore, there are also varied domains of human abilities that are claimed to be outside the scope of standard psychometric tests (Neisser et al., 1996). Some researchers also assert that intelligence is not a unitary ability, but a composite of several processes (Anastasi \& Urbina, 1997; Ceci, 1996).

Additionally, older adults frequently perform poorly on tests of general mental abilities, but actually function quite well in their daily living (Baltes, Smith, \& Staudinger, 1992; Denny \& Palmer, 1981; Horn, 1982;Sternberg, 1985). Therefore, the span of traditional ability tests may be too limited in identifying factors of intelligence that are critical for day-to-day existence. Furthermore, practical problem-solving abilities may increase with age because adults gain increasing experience in solving practical problems, and learn from these experiences on how to solve problems better (Cornelius \& Caspi, 1987). Essentially, the evidence tends to show that people with high IQ scores are likely to learn more, and remember more, than people with low IQs, and that moreover they are able to learn things faster than people with lower IQs. It only implies the probability that the training time that would be necessaryly longer, and more expensive, than for persons with higher cognitive skills (Carroll, 1997).

Additionally, job experience is a measure of practice on the job and therefore a measure of opportunity to learn. (Schmidt \& Hunter, 1998). Higher-IQ individuals learn faster and therefore become more knowledgeable in their jobs sooner (Perkins, 1995). However, a majority of the learning that improves performance occurs informally in the form of learning from an individual's own experience (Wagner, 1991,1997). Indeed, Schmidt \& Hunter (1998) found that education predicts training performance better than it predicts performance on the job. However, job experience does not predict 
performance in training programs teaching new skills (Schmidt \& Hunter, 1998, p.269). Furthermore, research supports that the essential factor in the development of expertise is the way in which facts are integrated and differentiated within an individual's knowledge base. Exposure to relevant information is therefore necessary but insufficient for expertise to develop (Hoffman, 1992).

Curiously, cognitive-ability tests have been known to be limited predictors of leadership performance, with correlations reported between .20 and .30 (Fiedler \& Link, 1994). Indeed, Fiedler \& Link (1994) found intelligent leaders to perform poorly when they experienced interpersonal stress. Additionally, Fiedler \& Link (1994) found that leader experience contributed to performance only when the individual was highly uncertain of what to do or must respond decisively under emergency situations. Also, the more intelligent leader's intellectual effort interfered with tasks that required experiencebased behavior. (Fiedler \& Link, 1994)

Furthermore, research on intelligence and culture claim the presence of abilities not measured by traditional cognitive ability measures. For example, Sternberg and Ruzgis, (1994) asserts that intelligence can be best understood as adaptation, but adaptation to the cultural meaning system, integrating and expressing cultural values. Different environmental demands connected with different cultures lead to the development of different patterns of ability and stress different types of cognitive characteristics that are valued (Bowers, 1999; Ceci, 1996; Sternberg \& Ruzgis, 1994). Cultural context is an important part of ability because the culture dictates the occurrence or nonoccurrence of events that are known to effect ability developments. One's ability tends to increase with age in those processes whose value is supported by one's culture 
and one's ability tends to decrease in those processes whose value is not supported. (Anastasi \& Urbina, 1997) Additionally, culture controls the frequency of occurrence of events, thus dictating the amount of time spent doing certain tasks instead of others (Ceci, 1996). For example, in a study by Okagaki and Sternberg (1993), parents of AngloAmericans did not value motivational, social skills, and practical school skills over cognitive characteristics for their children compared to other foreign national parents who valued these skills over cognitive characteristics in their conception of intelligence for their children.

Many researchers are critical of the psychometric approach to intelligence (Ceci, 1990). These critics find it difficult to establish theories of intelligence on test scores alone, ignoring many other types of intelligence (Carroll, 1993). Ceci (1996) asserts that there is not one intellectual factor $\mathrm{g}$ underlying most or all of the variance on intellectual tasks, but multiple cognitive factors. Researchers on multiple intelligences include Thurstone (1938), Thorndike (1913), Gardner (1983), Cattell (1887), and Sternberg (1985).

Thorndike (1913) viewed intelligence as consisting of many different, but related structures. He called his view of intelligence the "multi-factor theory of intelligence". Specifically, his theory incorporated three domains of intelligence: social, concrete, and abstract. Thorndike also included $\mathrm{g}$ or a general mental ability factor in his theory. Gardner's (1983) research concentrated on gifted individuals or savants. This research has given him new perspectives on how intelligence is defined. Gardner now includes musical, bodily kinesthetic, and other different types of intelligence in his theory. Specifically, Howard Gardner (1983) has asserted that there are seven types of 
intelligences. These include verbal and mathematico-logical, spatial, musical, personal intelligence (interpersonal skills), intrapsychic capacity, and kinesthetic ability. Social intelligence, another theory of multiple intelligence is described as the ability to comprehend the feelings, thoughts, and behaviors of individuals, including oneself, in interpersonal conditions and to act accordingly upon that understanding (Marlowe, 1985). It consists of a set of problem-solving skills that enable the individual to solve interpersonal problems (Marlowe, 1985). The data substantially supports a multidimensional model of social intelligence. Marlowe (1986) found that the social intelligence domain were distinct from the general intelligence domains.

Similar to social intelligence, emotional intelligence includes the accurate appraisal and expression of emotions in oneself and others and the regulation of emotion in a manner that improves the individual's existence in society (Mayer, DiPaolo, Salovey, 1990). Emotional intelligence incorporates the utilization of emotional information in problem solving. That is, numerous intellectual problems include emotional information that must be processed; this processing may proceed differently than the processing of nonemotional information (Mayer and Salovey, 1993).

\section{The relation of Learning Agility to Practical Intelligence}

Generally practical intelligence includes various types of knowledge and skills that are outside the realm of abilities associated with academic achievement. It contains abilities required by problems and tasks faced in an everyday context. Practical intelligence includes different types of achievement, where individuals differ in their 
experiences and the particular application of their general mental ability resources.

Neisser et al. (1996) describes the difference between analytic and practical problems:

Analytic problems, of the type suitable for test construction, tend to (a) have been formulated by other people, (b) be clearly defined, (c) come with all the information needed to solve them, (d) have only a single right answer, (e) be disembedded from ordinary experience, and (f) have little or no intrinsic interest. Practical problems, in contrast, tend to (a) require problem recognition and formulation, (b) be poorly defined, (c) require information seeking, (d) have various acceptable solutions, (e) be embedded in and require prior everyday experience, and (f) require motivation and personal involvement.

The triarchic theory seeks to view intelligence in terms of the context in which it occurs. The triarchic theory of human intelligence (Sternberg, 1985, 1988, 1996) states that intelligence consists of three aspects: analytical, practical, and creative. Sternberg, (1997) asserts that popular IQ tests only measure analytical intelligence and ignore creative and practical intelligence (Sternebrg, 1985).

Sternberg, Wagner, Williams, and Horvath (1995) found practical intelligence is relatively independent of general mental ability as measured by traditional tests, and it predicts job performance over and beyond the prediction of other types of traditional tests (Sternberg, Wagner, Williams, and Horvath, 1995). Success in almost any job requires practical skills that traditional intelligence inventories do not assess (Sternberg, 1996b).

Other researchers have found differences between traditional analytic intelligence tests and practical intelligence (Atwater, 1992; Carraher, Carraher, \& Shliemann, 1985; Ceci \& Liker,1986; Lave, 1988). Additionally, Nevo \& Chawarski (1997) found that a 
higher level of practical intelligence related positively with more successful adaptation in a new country.

A type of practical intelligence termed "tacit knowledge" is described as being acquired without formal instruction, that enables the acquisition of desirable goals (Wagner \& Sternberg, 1985). Wagner and Sternberg (1985) found tacit knowledge scores to be independent of scores on intelligence tests, yet related to job performance. Tacit knowledge does not appear to be closely related to performance on traditional inventories of verbal intelligence (Wagner \& Sternberg, 1985), Thus supporting the distinction between practical and analytical intelligence. Specifically, practical intelligent behavior in managerial tasks depends in part on tacit knowledge, divided into three factors: tacit knowledge about managing self, managing others, and managing career (Wagner \& Sternberg, 1985). Measures of tacit knowledge assess a relatively general construct (Sternberg, Wagner, Williams, \& Horvath, 1995).

Wagner and Sternberg (1990) assert that the product of learning that is critical to performance in real-world conditions is Tacit knowledge (knowledge that is not openly expressed or stated). Research has shown that experts differ from novices mainly in the amount and organization of their knowledge about a task, rather than any underlying cognitive ability (Ceci \& Liker, 1986).

Wagner and Sternberg (1990) found the correlation between tacit knowledge and IQ to be -.14 ( $\mathrm{p}>.05$ ), with Tacit knowledge accounting for an additional $32 \%$ of criterion variance over and above IQ. Additionally, Wagner and Sternberg (1990) found that after factoring out education and experience, tacit knowledge still explained a substantial share of the variance in success. 
Not all managers acquire tacit knowledge. Learning from experience, rather than just experience is critical in acquiring tacit knowledge. Comprehending why some managers benefit from their experience and others do not will necessitate an improved comprehension of individual differences in acquiring tacit knowledge, and also perhaps an improved understanding of the conditions that afford important information to be learned (McCall, Lombardo \& Morrison, 1990; Wagner \& Sternberg, 1990).

However, theories on nontraditional intelligence theories, such as multiple intelligence are not without critics. The recent theories on "multiple intelligences" rest on weak empirical foundations (Eysenck, 1998). Furthermore, the term "emotional intelligence" is misleading, as it is not a cognitive variable, but in reality comprises of several uncorrelated personality traits (Eysenck, 1998). Additionally, according to Jensen (1980) there is no evidence that the different types of practical intelligence intercorrelate highly enough to form a single factor independent of general mental ability. Lastly, contextualist theories are extremely inclusive in that they include within the realm of cognitive abilities what commonly might be positioned in the sphere of personality or motivation (Eysenck, 1998).

The theory of Learning Agility, or more specifically the factor of learning agility called mental agility can be linked to the vast research on intelligence. Eichinger and Lombardo's (1997) Mental Agility factor of Learning Agility describes individuals who are mentally fast, who deeply analyze problems, and are adept at communicating their rational to other individuals. Another factor of Learning Agility that relates to intelligence is Results Agility, which describes individuals who are capable of adapting to their environment in order to excel. Eichinger and Lombardo (1997) assert that the 
factor mental agility does not measure what traditional cognitive ability tests, and therefore mental agility should correlate only moderately with cognitive ability.

Eichinger and Lombardo (1997) compare their construct of learning agility to that of common sense or street smarts. Eichinger and Lombardo (1997) describe the factor, results agility, as including a strong component of adaption to one's environment to achieve goals. Indeed, recent research on practical intelligence presents a fluid connection between Eichinger and Lombardo's (1997) learning agility and practical intelligence research. In addition learning Agility is related to personality constructs theoretically and empirically (based on the scant available data). Therefore, I now turn to a discussion of the research on the use of personality in personnel selection.

\section{Personality}

Personality generally refers to traits inside individuals that explain consistent behavioral patterns towards environmental cues (Pervin, 1980). These traits also influence the interpersonal strategies that individuals have developed to relate to others. These traits of individuals are what drive their social behavior, and their responses to personality questionnaires (Hogan, Hogan, \& Roberts, 1996). Personality also refers to reputation or those interpersonal characteristics, described by those individuals who have seen that person in different situations.

Personality researchers generally concur that the existing personality inventories all measure the same five broad dimensions (Hogan et al., 1996). Many personality psychologists support this Five Factor Model as an adequate taxonomy (Costa \& McCrae, 1995; Digman, 1990;Goldberg, 1990; Murphy, 1996). The big five theory of 
personality is currently the dominant model in personality research, and this model has unified personality this research efficiently in its ability to classify the numerous personality variable theories in the field (Barrick \& Mount, 1991). The big five personality factors include: Agreeableness, Extraversion, Emotional Stability, Openness to Experience, and Conscientiousness.

\section{$\underline{\text { Agreeableness }}$}

Agreeableness generally measures how well an individual gets along with others. Courteousness, flexibility, compliance and tolerance are traits usually associated with this dimension. Recent research on agreeableness has shown it to be a valid predictor of training competency (Mount \& Barrick, 1998; Salgado, 1997).

Another study by Bernardin, Cooke and Villanova (2000) found that participants higher on Agreeableness obtained higher ratings of peer performance in group tasks. The participants consisted of 111 students who made peer evaluations on human resource management problems, and completed the NEO Five Factor Inventory. Results indicate a correlation of $\mathrm{r}=.33$ for Agreeableness and average peer rating.

$\underline{\text { Extraversion }}$

Extraversion pertains to how social an individual is with others. Traits that are included in the extraversion factor include being outgoing, expressive, forward, and conversational. Research has shown that individuals high on the factor of extraversion to perform well in sales related jobs (Vinchur, Schippmann, Switzer, \& Roth, 1998), but extraversion has also been found to positively predict absenteeism (Judge, Martocchio \& Thoresen, 1997). 
Judge and Bono (2000) found that Extraversion positively predicted transformational leadership. The participants, 539, completed the NEO Personality Inventory-Revised, the Transformational Leadership Behaviors survey, and several other measures. Extraversion correlated positively $(r=.22)$ with the combined four factors of Transformational leadership (i.e., Idealized influence, Inspirational motivation, Intellectual stimulation, and Individualized consideration).

Emotional Stability

Emotional Stability measures an individual's affective reactions to their environment. Traits of emotional stability may include depression, hostility, and excessive worrying. Research has shown that emotional stability predicts performance within team environments (Barrick, Stewart, Neubert \& Mount, 1998; Mount, Barrick \& Stewart, 1998).

Judge, Higgins, Thoresen, and Barrick (1999), examined the Big Five Personality factors and career success across the life span. Specifically, Judge et al. found that Emotional Stability was negatively related to extrinsic success $(r=-.34)$. Extrinsic success was defined in this study as income and occupational status (e.g., 1=higher executives to $7=$ unskilled employee $)$. The sample $(n=354)$ was from a set of studies called the Intergenerational Studies, that spread over 7 decades. This study showed that Emotional Stability was stable over time in relation to career success.

\section{Openness to Experience}

Openness to Experience measures the degree of openness an individual has to new experiences. Traits of this dimension include being cultured, curious, imaginative 
and open-minded. Current research on openness to experience also found it to be a valid predictor of training competency (Mount \& Barrick, 1998; Salgado, 1997).

Caligiuri (2000) examined personality and willingness to quit an expatriate assignment. The participants consisted of 143 expatriate employees, who completed the Hogan Personality Inventory (HPI), and willingness to quit an expatriate assignment. Surprisingly, Openness to Experience was not related to willingness to quit an expatriate assignment. One would expect Openness to experience to negatively correlate with a willingness to quit an expatriate assignment. Caligiuri (2000) explained the measure used may have tapped a cognitive facet rather then a perceptual facet of Openness to Experience, or that different subfactors of Openness to experience may be essential to an expatriates' achievement.

\section{Conscientiousness}

Conscientiousness measures an individual's ability to persevere against obstacles and diligently do what is expected to be done in a responsible manner. The personality trait of Conscientiousness has been found to correlate the highest with job performance (Barrick \& Mount, 1991). Conscientious individuals have also been found to be disciplined and persevere despite set backs in performance. Also, conscientiousness interacts with $\mathrm{g}$, which relates to individual differences in achievement and vocational aptitude (Jensen, 1998). However, Mount, Barrick and Strauss (1999) found that although conscientiousness has incremental validity over general mental ability in predicting job performance, they found that there is no interaction (e.g., beyond main effects) between the two in predicting job performance. Additionally, research has also 
found that, controlling for mental ability, individuals who are higher in conscientiousness develop higher levels of job knowledge, possibly because highly conscientious individuals expand greater efforts and spend more time on the current task (Schmidt \& Hunter, 1998).

Numerous researchers have found strong relationships between personality and job performance (e.g. Barrick \& Mount, 1991; Borman, Hanson, \& Hedge, 1997; Hogan, Hogan, \& Roberts, 1996). Barrick and Mount (1991) found a relationship between training proficiency and openness to experience. Ones, Viswesvaran, \& Schmidt (1993) found that integrity test scores are strong predictors of job performance and counterproductive behaviors on the job. Personality factors of openness to experience and agreeableness closely match cognitive ability inventories in predicting job performance (e.g. corrected mean r's of .27 and .33 respectively; Hogan et al., 1996). McDaniel and Frei (1994) found that customer service measures, containing facets of the Big-Five dimensions of agreeableness and emotional stability, have a mean validity of .50 in predicting performance in service jobs (Hogan et al., 1996).

The theory of Learning Agility can also be linked to the big five-personality theory. Eichinger and Lombardo's (1997) People Agility, a factor of Learning Agility describes individuals who are open to different types of people and ideas, who are agreeable in their interactions with others, calm under intense situations, and have a good understanding of themselves. Results Agility is the ability that enables individuals to succeed under difficult circumstances, who have a personal drive that helps them achieve results. Thus, there is conceptual evidence suggesting that these learning agility factors are related to personality constructs. 
In addition to cognitive ability and personality variables, I/O Psychologists have examined the effects of goals on performance. Goal orientation has been conceptualized as a dispositional trait as well. Learning Agility can be theoretically linked to goal orientation. I turn to a discussion of the role of goals in I/O psychology next.

\section{Goal Orientation}

Goals are one of the most influential cognitive factors affecting job performance (Locke, 1968). Goals focus individuals on the task at hand, aid in the development of tactics, and help in maintaining persistence at completing tasks (Locke, 1968). Locke has been a major contributor of goal setting research that suggests that individuals with difficult, and specific goals out perform individuals with no goals ( Locke, Chah, Harriosn, \& Lustgarten, 1989). Locke and his colleagues have also examined goal commitment (Locke, Latham, \& Erez, 1988). According to Locke and his colleagues, there are three determinants of goal commitment: external factors, interactive factors, and internal factors. Hollenbeck and Klein (1987) proposed another model of goal commitment consisting of two determinants: expectancy of goal attainment and valence of goal attainment. Both models of goal commitment include personality factors or “internal factors" (Locke, Latham, \& Erez, 1988), or "personal factors" (Hollenbeck \& Klein, 1987) that aid in determining goal commitment levels achieved by individuals. Specifically, a personality trait called Goal Orientation has been proposed that states that individual's have a preference in how they approach achieving their goals (Dweck, 1986). Goal orientation has been conceptualized as being made up of two factors termed learning goal orientation and performance goal orientation (Button et al., 
1996; VandeWalle, 1997). Learning oriented individuals' focus on building new competencies, where performance goal oriented individuals focus on meeting expected standards of competence (e.g., Button et al., 1996; VandeWalle, 1997). Elliott and Dweck (1988) found that individuals with high performance goal orientations reacted negatively to perceived difficult tasks and also avoided perceived difficult tasks as well. Performance goal oriented individuals believe that ability is fixed, and focus on ability decrements and off-task thoughts (Button et al., 1996; Bobko \& Colella, 1994). Elliott and Dweck (1988) also found that individuals high on the learning goal orientation disposition persevered through perceived difficult tasks because they believed that competency can be improved to accomplish the task. Research has shown that individuals with high learning goal orientations engage in problem solving and change strategies in the face of poor performance (Dweck \& Leggett, 1988; Elliott \& Dweck, 1988).

Research has also shown that learning goal oriented individuals react to difficult tasks in a positive manner, perceiving the chance to increase competence. VandeWalle and Cummings (1997) report a positive correlation between learning goal orientation and feedback seeking. Additionally, VandeWalle, Brown, Cron, \& Slocum, Jr., (1999) found a positive relationship $(\mathrm{r}=.33)$ between learning goal orientation and performance. The sample consisted of 167 sales personnel, who completed a goal orientation measure, and performance was measure by units sold. It was found that performance goal oriented individuals used a maladaptive coping style that inhibited performance in the face of difficulty, while learning goal oriented individuals used an adaptive coping style in the face of difficulty that enabled them to excel (Vandewalle et al., 1999). 
Colquitt and Simmering (1998), found conscientiousness and learning goal orientation to be positively correlated with motivation to learn $(r=.43$ and $r=.47$ respectively), and found performance goal orientation negatively correlated with motivation to learn $(r=-.21)$. The sample consisted of 103 undergraduate students who completed several measures including a goal orientation measure, a motivation to learn measure, and a conscientiousness measure.

In conditions where difficulty in mastering training content is anticipated, results point out that highly learning goal oriented individuals (and less performance goal oriented individuals) should stay motivated. High learning oriented individuals similar to high learning agile individuals should remain highly motivated in new first time difficult situations.

Button et al. (1996) found that college GPA was positively related to learning goal orientation, and SAT scores were not correlated to learning goal orientation. This shows a distinction between cognitive ability (i.e., SAT score) and learning goal orientation. Likewise change agility, which is conceptually similar to Learning goal orientation and thus should not be positively correlated to cognitive ability.

Lastly, the theory of Learning Agility can be linked to goal orientation research. Eichinger and Lombardo's (1997) Change Agility which is a factor of Learning Agility is conceptually similar to learning goal orientation, which is a factor of goal orientation. Also, Results Agility is conceptually similar to performance goal orientation.

Eichinger and Lombardo (1997) describe Change Agile individuals as seizing new opportunities in order to learn, and in fact relish the challenge of new experiences in order to learn. In fact, research has revealed a positive relationship between motivation 
to learn and learning across various different situations ( Baldwin et al., 1991; Martocchio \& Webster, 1992; Phillips \& Gully, 1997).

\section{$\underline{\text { Summary and Hypothesis }}$}

Succession planning is an important process of determining who is going to be promoted into key positions in the near future. Traditional cognitive ability variables are strong predictors of job performance. However, they only account for about $25 \%$ of the variance in job performance. Additionally, research on personality variables in combination with cognitive ability variables has also contributed substantially to the accounting of additional variance in job performance. This research points out that a combination of a cognitive ability test and integrity test (which measures mostly conscientiousness) has the highest validity (.65) for predicting job performance (Schmidt \& Hunter, 1998).

Intelligence research is now extending beyond examining traditional cognitive ability variables to other important abilities in order to attempt to account for more of the variance in job performance. Practical intelligence is a promising stream of research that has been shown to predict job performance over and beyond cognitive ability measures. Recently, Eichinger and Lombardo's (1997) Learning Agility construct is such an alternative construct that has also been shown to predict job performance/potential. However, research on the construct validity of Learning Agility is needed to further understand Learning Agility and to guide further research.

This study aims to increase the research on this new construct called Learning Agility by examining its relationship with job performance/promotability and by 
conducting a construct validity study using established measures of cognitive ability, personality, and goal orientation. This study will determine if Learning Agility is distinct from cognitive ability and/or personality, and reaffirm its relationship with job promotability.

An improved understanding of Learning Agility can have important contributions to selection research and to succession planning systems. Theoretically this study will contribute to the intelligence research by expanding the knowledge base of alternative abilities such as practical intelligence or tacit knowledge.

In this dissertation, I will assess the construct validity of the Choices Questionnaire as well as its relationship to job performance and to job promotability. Towards this end, the theory behind the Choices Questionnaire will be linked to theories of intelligence, personality, and goal orientation.

The hypotheses are summarized below:

1a. Mental Agility should show a positive correlation with openness to experience. lb. Mental Agility should not show a significant correlation with Conscientiousness, extraversion, Agreeableness, and Emotional Stability.

1c. Mental Agility should show a moderate positive correlation with cognitive ability. 1d. Mental Agility should not show a significant correlation with Learning Goal Orientation.

1e. Mental Agility should not show a significant correlation with Performance Goal Orientation. 
2a. Change Agility should show a positive correlation with openness to experience.

2b. Change Agility should not show a significant correlation with Conscientiousness, extraversion, Agreeableness, and Emotional Stability.

2c. Change Agility should not show a significant correlation with cognitive ability.

2d. Change Agility should show a significant correlation with Learning Goal Orientation.

2e. Change Agility should not show a significant correlation with Performance Goal Orientation.

3a. People Agility should show a positive correlation with Extraversion, Agreeableness, and Emotional Stability.

3b. People Agility should not show a significant correlation with Conscientiousness, and Openness to Experience.

3c. People Agility should not show a significant correlation with cognitive ability.

3d. People Agility should not show a significant correlation with Learning Goal Orientation.

3e. People Agility should not show a significant correlation with Performance Goal Orientation.

4a. Results Agility should show a positive correlation with Conscientiousness.

4b. Results Agility should not show a significant correlation with Extraversion, Openness to Experience, Agreeableness, and Emotional Stability.

4c. Results Agility should not show a significant correlation with cognitive ability.

4d. Results Agility should not show a significant correlation with Learning Goal Orientation. 
4e. Results Agility should show a positive correlation with Performance Goal Orientation.

5a. Learning Agility should show a strong positive correlation with supervisor ratings of job performance.

5b. Learning Agility should show a strong positive correlation with supervisor ratings of job promotability.

6a. Learning Agility should predict, over and beyond cognitive ability and personality, supervisor ratings of job promotability.

6b. Learning Agility should predict, over and beyond cognitive ability and personality, supervisor ratings of job performance.

\section{METHOD}

\section{$\underline{\text { Participants }}$}

A total of 310 survey packets were sent out to law enforcement personnel across the country and 130 survey packets were returned for a response rate of $42 \%$. Participants consisted of 510 law enforcement officers from 26 organizations across the United States. Twenty-three of the data points (e.g., data point $=1$ participant, 1 supervisor, $\& 2$ coworkers) were found to be unusable, and were eliminated from the analysis. The final sample contained 418 participants, or 107 complete data points (5 supervisors participated twice and 5 participants also participated as a coworker for another particpant). The participants were $80 \%$ male, and $20 \%$ female. More then half of the 
participants $(68 \%)$ had tenure in their organization of 10 years or more. Participant ethnicity broke down into 3 major groups: $65 \%$ of Anglo-Saxon origin, 15\% of Hispanic origin, and $13 \%$ of African-American origin. Additionally, slightly half of the participants $(53 \%)$ were under 40 years of age.

\section{$\underline{\text { Measures }}$}

Cognitive Ability: Watson Glaser Critical Thinking Appraisal: The Watson Glaser Critical Thinking Appraisal consists of 40 items and measures five aspects of the ability to think critically: Inference - Drawing Inferences from facts, Recognition of Assumptions - Recognizing assumptions implied by a statement, Deduction - Reasoning by deduction, Interpretation - Reasoning logically by interpretation, Evaluation of Arguments - Discriminating between strong and weak arguments. The coefficient alpha for the Watson Glaser reported in the manual is .81 .

Personality: International Personality Item Pool (IPIP). The FFM of personality was assessed using the Goldberg 50 item IPIP, which provides an assessment of the major Big 5 dimensions of Neuroticism (N), Extraversion (E), Openness to Experience (O), Agreeableness (A) and Conscientiousness (C). The scales of the IPIP demonstrate good internal reliability (coefficient alpha's ranging between $.77-.86$ for the five scales). Also, the factors of the IPIP have been shown to correlate between 0.77 to 0.82 with the equivalent NEO factors.

An example of a Neuroticism item is, "Get stressed out easily". An example of an Openness to Experience item is, "Have a vivid imagination". An example of 
Agreeableness item is, "Make people feel at ease". An example of a Conscientiousness item is, "Am always prepared". An example of Extraversion is, "Am the life of the party".

Goal orientation. A sixteen-item dispositional goal orientation measure developed by Button et al.'s (1996) was used. The eight item performance goal orientation scale has a coefficient alpha of .78. The eight item learning goal orientation scale has a coefficient alpha of .79. The response scale used ranged from (1) "strongly disagree" to (7) "strongly agree".

An example of a Learning Goal Orientation item is, "I prefer to work on tasks that force me to learn new things". An example of a Performance Goal Orientation item is, "I prefer to do things that I can do well rather than things that I do poorly".

Choices Questionnaire. The "Choices" questionnaire is a set of 76 behavior items that is designed to be completed on a target individual by someone the individual knows (i.e., a supervisor or a coworker). That is, the supervisor or coworker completes the Choices Questionnaire on the individual to be rated. The questionnaire purports to measure four factors: "People Agility", "Results Agility", "Mental Agility", and "Change Agility". "Mental Agility" describes individuals who think through problems from a fresh point of view, are comfortable with complexity, ambiguity and explaining their thinking to others. An example of an item from the Choices Questionnaire on Mental Agility is, "Can combine the best parts of more than one idea or solution from multiple people and sources into a net better idea or solution." "People Agility" describes individuals who know themselves well, learn from experience, treat others constructively, and are cool and resilient under the pressures of change. An example of an item from the Choices 
Questionnaire on "People Agility" is, "Knows that change is unsettling; can take a lot of heat, even when it gets personal". "Results Agility" describes people, who get results under tough conditions, inspire others to perform beyond normal, and exhibit the sort of presence that builds confidence in others. An example of an item from the Choices Questionnaire on "Results Agility" is, "Can inspire a team to work hard". "Change Agility" describes individuals who are comfortable and look forward to experiencing new situations and challenges. An example of an item from the Choices Questionnaire on "Change Agility" is, "Seeks and looks forward to opportunities for new learning experiences in business or personal areas".

In this study the alpha coefficients for the four factors ranged from .91 to .95 for the four factors.

Job Performance Evaluation form: Several law enforcement agencies provided a copy of their performance review form. These performance review forms were content analyzed, and from this analyses a generic job performance evaluation form was created. The job performance evaluation form consists of 11 performance dimensions (along with their definitions), 1 overall performance dimension, and 1 promotability dimension. The 11 performance dimensions are as follows:

1. Communication: Speaks and writes clearly and concisely; listens actively and understands key pieces of spoken information.

2. Judgment: Applies policies and procedures properly and demonstrates "common sense" in handling day- to- day situations. Evaluates and understands the consequences of ones own actions. 
3. Problem Solving: Recognizes or identifies the existence of problems and solves them or offers potential solutions.

4. Decision Making: Accurately diagnoses situations and takes appropriate action.

5. Planning \& Organizing: Defines the tasks and /or goals that must be accomplished. Provides a framework or strategy for accomplishing these tasks/goals, and establishes a timeline for completion.

6. $\quad$ Professional Demeanor: Maintains business like conduct and appearance. Acts responsibly and honestly in all roles and responsibilities.

7. Initiative: Performs well without direct supervision and suggests new methods or procedures to improve operations.

8. Interpersonal Relations: Develops, cooperates, and maintains positive productive working relationships with other individuals; empathizes with the concerns of others.

9. Dependability: Performs job responsibilities reliably and as scheduled. Delivers on promises made to other individuals.

10. Stress Tolerance: Works effectively under stressful or unusually demanding conditions. Maintains composure and stability when confronted by aggressive or argumentative individuals.

11. Job Knowledge: Appropriately applies governmental laws/ordinances, department policies/ procedures, weaponry/equipment to job tasks and responsibilities. 
The coefficient alpha for these 11 items of job performance is .92. Based on this high coefficient alpha, the overall job performance rating was used as a proxy in the analyses. Additionally, a composite of the 11 performance dimensions was also used in the analyses.

Procedure

A contact person within each law enforcement department coordinated the distribution of the questionnaire packets down through the chain of command. A participant filled out a set of self-report measures, and two co-workers completed a questionnaire on that participant. Finally, a supervisor completed a performance appraisal on the participant. Questionnaires consisting of an instruction sheet, an informed consent agreement, a demographic information sheet, the IPIP personality inventory, the Watson-Glaser Critical Thinking inventory, and the Goal Orientation measures were included in the packet for participant 1. The packet for the co-worker consisted of an instruction sheet, an informed consent agreement form, a demographic information sheet and the Choices Questionnaire. The supervisor packet consisted of an instruction sheet, an informed consent agreement form, and a performance appraisal form (includes a demographic information sheet). Participants turned in all materials to the designated contact person enclosed in tamper evident envelopes.

Participants were advised that the information obtained would remain confidential and the data would be used for research purposes only. 


\section{RESULTS}

Zero-order correlations between all the variables and Cronbach's alpha reliability coefficients were tabulated for all measures (Table 1). Coefficient alpha reliabilities were tabulated for the Learning Agility questionnaire, along with the 4 Learning Agility scales of the Choices Questionnaire, Watson-Glaser Critical Thinking Appraisal, the IPIP, and the two Goal Orientation scales.

The four Learning Agility factors, which were averaged across the 2 coworkers, correlated highly with each other and ranged from $r=.80$ to $r=.97$, with an average correlation or $r=.86$. The Big Five Personality factors correlated from $r=-.04$ to $r=$ .30 , with an average correlation of $r=.16$. The IPIP Manual reports the average correlation between the Big Five to be $\mathrm{r}=.17$ (Goldberg, 2000), which was consistent with the current findings in this study. The factor loadings of the 50 items on the five factors are provided in Table 2 and the means and standard deviations are provided in Appendix $\mathrm{G}$. The correlations among the 11 performance dimensions ranged from $\mathrm{r}=$ .35 to $\mathrm{r}=.74$, with an average correlation of $\mathrm{r}=.55$. Furthermore, the correlation $(\mathrm{r}$ $=.76$ ) between Supervisory ratings of Overall Job Performance ratings and Supervisor ratings of Job Promotability was strong. This finding is indicative that supervisors judgements of job promotability and current job performance are strongly correlated.

A confirmatory factor analysis was used to confirm the Button et al. (1996) twofactor structure of Goal Orientation. This analysis should be viewed with caution. Due to the small sample size $(\mathrm{n}=107)$, the results may be unreliable (Tabachnick \& Fidell, 2001). Nevertheless, the AMOS program (Arbuckle, 1995) was used to carry out the analysis which resulted in several fit indices including, goodness-of-fit index (GFI), 
adjusted goodness-of-fit (AGFI), the root mean squared residual (RMR), and the root mean square error of approximation (RMSEA). Results of the two-factor model indicated the GFI (.79) and the AGFI (.72) did provide a poor fit. A value of 1 indicates the best fit for both the GFI and AGFI fit indices. The RMR (.19) and the RMSEA (.11) also indicated that fit could be improved over the two factor model. A value of 0 indicates the best fit for the RMR and the RMSR fit indices. Indeed, all of the fit indices suggest that improvements can be made to the two factor model. However, to be consistent with existing literature on this measure, I will continue to use the two factor solution here. Furthermore, a one factor model of Goal Orientation suggested a weaker support than did the two Factor model. The fit indices for the one factor model included the GFI (.66), the AGFI (.56), the RMR (.34), and the RMSEA (.16). Also provided in Table 3 are the factor loadings of the items in their respective factors.

Hypothesis la stated that Mental Agility should show a positive correlation with openness to experience. This hypothesis was supported. There was a small but significant correlation $(\mathrm{r}=.21)$ between Mental Agility and Openness to Experience. Hypothesis 1b stated that Mental Agility should not show a significant correlation with Conscientiousness, extraversion, Agreeableness, and Emotional Stability. This hypothesis was supported. There was a non-significant correlation between Mental Agility and: Conscientiousness $(\mathrm{r}=-.01)$, Extraversion $(\mathrm{r}=.02)$, Agreeableness $(\mathrm{r}=.08)$, and Emotional Stability $(\mathrm{r}=-.03)$. Hypothesis $1 \mathrm{c}$ stated that Mental Agility should show a moderate positive correlation with cognitive ability. This hypothesis was not supported. There was a non-significant correlation $(r=.10)$ between Mental Agility and Cognitive Ability. Hypothesis 1d stated that Mental Agility should not show a significant 
correlation with Learning Goal Orientation. This hypothesis was supported. There was a non-significant correlation $(\mathrm{r}=.12)$ between Mental Agility and Learning Goal Orientation. Hypothesis le stated that Mental Agility should not show a significant correlation with Performance Goal Orientation. This hypothesis was not rejected. The small correlation $(\mathrm{r}=.18)$ between Mental Agility and Performance Goal Orientation was not significant.

Hypothesis 2a stated that Change Agility should show a positive correlation with openness to experience. This hypothesis was supported. There was a small but significant correlation $(\mathrm{r}=.23)$ between Change Agility and Openness to Experience. Hypothesis $2 \mathrm{~b}$ stated that Change Agility should not show a significant correlation with Conscientiousness, extraversion, Agreeableness, and Emotional Stability. This hypothesis was not rejected. There was a non-significant correlation between Change Agility and: Conscientiousness $(r=-.06)$, Extraversion $(r=.11)$, Agreeableness $(r=.08)$, and Emotional Stability $(r=-.06)$. Hypothesis $2 \mathrm{c}$ stated that Change Agility should not show a significant correlation with cognitive ability. This hypothesis was not rejected. There was a non-significant correlation $(r=.11)$ between Change Agility and Cognitive Ability. Hypothesis $2 \mathrm{~d}$ stated that Change Agility should show a positive correlation with Learning Goal Orientation. This hypothesis was not supported. There was a nonsignificant correlation $(\mathrm{r}=.13)$ between Change Agility and Learning Goal Orientation. Hypothesis 2e stated that Change Agility should not show a significant correlation with Performance Goal Orientation. This hypothesis was supported. There was a nonsignificant correlation $(\mathrm{r}=.08)$ between Change Agility and Performance Goal Orientation. 
Hypothesis 3 a stated that People Agility should show a positive correlation with Extraversion, Agreeableness, and Emotional Stability. This hypothesis was not supported. There was a non-significant correlation between People Agility and: Extraversion $(\mathrm{r}=-.01)$, Agreeableness $(\mathrm{r}=.04)$, and Emotional Stability $(\mathrm{r}=-.02)$. Hypothesis $3 \mathrm{~b}$ stated that People Agility should not show a significant correlation with Conscientiousness, and Openness to Experience. This hypothesis was supported. There was a non-significant correlation between People Agility and: Conscientiousness ( $r=-$ $.07)$, and Openness to Experience $(\mathrm{r}=.10)$. Hypothesis $3 \mathrm{c}$ stated that People Agility should not show a significant correlation with cognitive ability. This hypothesis was supported. There was a non-significant correlation $(r=.07)$ between People Agility and Cognitive Ability. Hypothesis $3 \mathrm{~d}$ stated that People Agility should not show a significant correlation with Learning Goal Orientation. This hypothesis was supported. There was a non-significant correlation $(r=.09)$ between People Agility and Learning Goal Orientation. Hypothesis 3e stated that People Agility should not show a significant correlation with Performance Goal Orientation. This hypothesis was supported. There was a non-significant correlation $(r=.09)$ between People Agility and Performance Goal Orientation.

Hypothesis 4a stated that Results Agility should show a positive correlation with Conscientiousness. This hypothesis was not supported. There was a non-significant correlation $(r=-.06)$ between Results Agility and Conscientiousness. Hypothesis $4 \mathrm{~b}$ stated that Results Agility should not show a significant correlation with Extraversion, Openness to Experience, Agreeableness, and Emotional Stability. This hypothesis was supported. There was a non-significant correlation between Results Agility and: 
Extraversion $(r=-.01)$, Openness to Experience $(r=.10)$, Agreeableness $(r=.12)$, and Emotional Stability $(\mathrm{r}=.03)$. Hypothesis $4 \mathrm{c}$ stated that Results Agility should not show a significant correlation with cognitive ability. This hypothesis was supported. There was a non-significant correlation $(\mathrm{r}=.03)$ between Results Agility and Cognitive Ability.

Hypothesis 4d stated that Results Agility should not show a significant correlation with Learning Goal Orientation. This hypothesis was supported. There was a non-significant correlation $(r=.12)$ between Results Agility and Learning Goal Orientation. Hypothesis 4e stated that Results Agility should show a positive correlation with Performance Goal Orientation. This hypothesis was not supported. There was a non-significant correlation $(\mathrm{r}=.11)$ between Results Agility and Performance Goal Orientation.

Hypothesis5a stated that Learning Agility should show a strong positive correlation with supervisor ratings of job performance. This hypothesis was supported. There was a significant correlation $(r=.37)$ between Learning Agility and Job Performance. Hypothesis $5 \mathrm{~b}$ stated that Learning Agility should show a strong positive correlation with supervisor ratings of job promotability. This hypothesis was also supported. There was a significant correlation of .40 between Learning Agility and Job Promotability.

Hypothesis 6a. Learning Agility should predict over and beyond cognitive ability and personality on the supervisor rating of job performance. In order to test this prediction, hierarchical regression analyses, with mean replacement for missing values, were conducted (Table 4). Supervisor ratings of overall job performance was regressed onto cognitive ability at step 1, the Big Five Personality factors at step 2, and Learning Agility at step 3. Learning Agility was found to account for $6 \%$ of the variance in 
supervisor ratings of overall performance over and beyond cognitive ability and personality. The $F=7.489(\mathrm{df}=1,99)$, and the change in $\mathrm{R}$-squared was .16 .

Additionally, another hierarchical regression analyses was conducted, with mean replacement for missing values (Table 6). Supervisor ratings of a composite of the 11 job performance dimensions was regressed onto cognitive ability at step 1, the Big Five Personality factors at step 2, and Learning Agility at step 3. Learning Agility was found to account for $11 \%$ of the variance in supervisor composite ratings of the $11 \mathrm{job}$ performance dimensions over and beyond cognitive ability and personality. The $\mathrm{F}=$ $13.538(\mathrm{df}=1,99)$, and the change in $\mathrm{R}$-squared was .11 . Thus, the hypothesis that Learning Agility should predict over and beyond cognitive ability and personality on supervisor ratings of job performance was supported.

Hypothesis $6 \mathrm{~b}$. Learning Agility should predict over and beyond cognitive ability and personality on the supervisor rating of job promotability. In order to test this prediction, hierarchical regression analyses, with mean replacement for missing values, again were conducted (Table 5). Supervisor ratings of promotability was then regressed onto cognitive ability at step 1, the Big Five Personality factors at step 2, and Learning Agility at step 3. Learning Agility was found to account for $10 \%$ of the variance in supervisor ratings of promotability over and beyond cognitive ability and personality. Also, the $F=11.701(\mathrm{df}=1,99)$, and the change in $\mathrm{R}$-squared was .10 . Thus, the hypothesis that Learning Agility should predict over and beyond cognitive ability and personality on supervisor ratings of promotability was supported. 


\section{DISCUSSION}

The purpose of this study was to examine the theoretical underpinnings and the construct validity of a measure that purports to predict an individual's potential performance in new tasks by examining the convergent/discriminant validity of the new measure against both a cognitive ability measure and two personality measures. This new measure may have considerable value if this new measure represents a construct that is unique to the cognitive ability and the two personality measures. This study also examined the relationship of this new measure to job performance and job promotability.

Additionally, researchers have started to examine the individual difference among individuals that differentially enable individuals to learn from their experiences and apply this to excel in new experiences or jobs (Eichinger \& Lombardo, 1997). Specifically, this study examined the construct and the criterion related validity of the Choices Questionnaire (Eichinger and Lombardo, 1997) which purports to predict an individual's potential in new jobs.

The first set of hypotheses (i.e., 1a-1e) examined the anticipated relationships between Mental Agility and the other measures in the study. Specifically, hypothesis 1a stated that Mental Agility should show a significant correlation with openness to experience. This hypothesis was supported. Hypothesis $1 \mathrm{~b}$ stated that Mental Agility should not show a significant correlation with Conscientiousness, extraversion, Agreeableness, and Emotional Stability. This hypothesis was supported. Hypothesis 1c stated that Mental Agility should show a moderate significant correlation with cognitive ability. This hypothesis was not supported. Hypothesis $1 \mathrm{~d}$ stated that Mental Agility should not show a significant correlation with Learning Goal Orientation. This 
hypothesis was partially supported. Hypothesis 1e stated that Mental Agility should not show a significant correlation with Performance Goal Orientation. This hypothesis was partially supported. Although there was a non-significant relationship between Mental Agility and cognitive ability, there was general support of these first hypotheses that provide evidence theorized earlier in this study that Mental Agility is similar to Openness to Experience and different from the other variables in the study. That is, the construct of Mental Agility is convergent with like constructs (i.e., Openness to Experience) and divergent from unlike constructs (i.e., Conscientiousness, Extraversion, Emotional Stability, Agreeableness, Goal Orientation, and cognitive ability). This represents the first piece of evidence generally supporting the construct validity of Learning Agility. The second set of hypotheses (i.e., $2 \mathrm{a}-2 \mathrm{e}$ ) examined the anticipated relationships between Change Agility and the other measures in the study. Specifically, hypothesis $2 \mathrm{a}$ stated that Change Agility should show a significant correlation with openness to experience. This hypothesis was partially supported. Hypothesis $2 \mathrm{~b}$ stated that Change Agility should not show a significant correlation with Conscientiousness, extraversion, Agreeableness, and Emotional Stability. This hypothesis was supported. Hypothesis 2c stated that Change Agility should not show a significant correlation with cognitive ability. This hypothesis was supported. Hypothesis $2 \mathrm{~d}$ stated that Change Agility should show a significant correlation with Learning Goal Orientation. This hypothesis was not supported. Hypothesis 2e stated that Change Agility should not show a significant correlation with Performance Goal Orientation. This hypothesis was supported. Again, although the relationship between Change Agility and learning goal orientation was not significant, the second set of hypotheses lends general support to the construct validity of 
Learning Agility. Specifically, that the convergent and divergent validity of Change Agility with similar and dissimilar established constructs was generally supported in this study.

The third set of hypotheses (i.e., $3 \mathrm{a}-3 \mathrm{e}$ ) examined the anticipated relationships between People Agility and the other measures in the study. Specifically, hypothesis 3a stated that People Agility should show a significant correlation with Extraversion, Agreeableness, and Emotional Stability. This hypothesis was not supported. Hypothesis $3 b$ stated that People Agility should not show a significant correlation with Conscientiousness, and Openness to Experience. This hypothesis was supported. Hypothesis $3 \mathrm{c}$ stated that People Agility should not show a significant correlation with cognitive ability. This hypothesis was supported. Hypothesis $3 \mathrm{~d}$ stated that People Agility should not show a significant correlation with Learning Goal Orientation. This hypothesis was supported. Hypothesis $3 \mathrm{e}$ stated that People Agility should not show a significant correlation with Performance Goal Orientation. This hypothesis was supported. The factor of People Agility did not converge with the variables hypothesized, however, it did diverge from variables hypothesized. The mixed results of this set of hypotheses did not lend support to the construct validity of Learning Agility.

The fourth set of hypotheses (i.e., $4 \mathrm{a}-4 \mathrm{e}$ ) examined the anticipated relationships between Results Agility and the other measures in the study. Specifically, hypothesis 4a stated that Results Agility should show a significant correlation with Conscientiousness. This hypothesis was not supported. Hypothesis $4 \mathrm{~b}$ stated that Results Agility should not show a significant correlation with Extraversion, Openness to Experience, Agreeableness, and Emotional Stability. This hypothesis was supported. Hypothesis $4 \mathrm{c}$ stated 
that Results Agility should not show a significant correlation with cognitive ability. This hypothesis was supported. Hypothesis $4 \mathrm{~d}$ stated that Results Agility should not show a significant correlation with Learning Goal Orientation. This hypothesis was supported. Hypothesis 4e stated that Results Agility should show a significant correlation with Performance Goal Orientation. This hypothesis was not supported. Hypothesis four stated that Results Agility would significantly correlate with conscientiousness, and Performance Goal Orientation. Although Results Agility did diverge from the hypothesized variables in the study, Results Agility correlated non-significantly with Performance Goal Orientation, this hypothesis was generally not supported. Again these sets of hypotheses reported mixed evidence regarding the construct validity of Results Agility. However, supervisor ratings of dependability, generally known as a factor of conscientiousness, correlated moderately with Results Agility $(r=.23, p<.05)$. It appears that supervisors and coworkers are seeing similar behaviors in the participants being rated.

Hypothesis $5 \mathrm{a}$ and $5 \mathrm{~b}$ stated that Learning Agility should show a strong significant correlation with supervisor ratings of job performance, and supervisor ratings of job promotability. These hypotheses were partially supported. There was a moderate significant correlation between Learning Agility - Job Performance $(r=.37)$ and a moderately strong significant correlation $(\mathrm{r}=.40)$ between Learning Agility and Job Promotability. Indeed, this shows that individuals who are high on Learning Agility are also strong performers in their organization. This also positions Learning Agility among those constructs, such as cognitive ability and personality that are traditionally strong predictors of job performance. 
Hypothesis $6 \mathrm{a}$ and $6 \mathrm{~b}$ stated that Learning Agility should predict over and beyond cognitive ability and personality on the supervisor rating of job performance and job promotability. This set of hypotheses were supported. This suggests that Learning Agility's central claim of predicting those individuals who will succeed in new jobs or environments is supported. Furthermore, that Learning Agility predicts unique variance in job performance and job promotability over such stalwart constructs such as cognitive ability and personality is a valuable contribution to personnel selection research.

\section{Theoretical Implications}

This research generally supports the addition of Learning Agility into the nomological net of succession planning predictors. The results of this study suggest that Learning Agility is weakly related to openness to experience and not related to the other four personality factors. Learning Agility is also different from cognitive ability. Furthermore, Learning Agility may fall into the realm of noncognitive constructs relating to adaptability and knowledge acquisition.

Although Hypotheses $3 \mathrm{a}$ and $4 \mathrm{a}$ were not supported, the supervisor ratings (i.e., Interpersonal Relations, Decision Making, and Professional Demeanor) that relate to these hypotheses did support the construct validity of Learning Agility. That is, coworkers and supervisors were viewing similar competencies in the participants being rated. Perhaps the low correlations between the self- report personality responses and the others' ratings (i.e., Coworkers and supervisors) responses is due to an inaccurate selfperception of the participant (Harris \& Schaubroeck, 1988). However, self-other agreement is very complicated, and many factors may effect this relationship, such as 
human perceptions (Atwater, Ostroff, Yammarino, \& Fleenor, 1998). Additionally, Connolly and Viswesvaran (1999) examined through the method of meta-analysis the convergent validity between self and observer ratings of the Big Five Personality traits. The mean correlation corrected for coefficient alpha in self-ratings and interrater reliability in observer ratings was: .46 for Agreeableness $(\mathrm{N}=6,359, \mathrm{k}=53), .56$ for Conscientiousness ( $\mathrm{N}=6,754, \mathrm{k}=58), .51$ for Emotional Stability $(\mathrm{N}=8,000, \mathrm{k}=55)$, .62 for Extraversion $(\mathrm{N}=7,725, \mathrm{k}=50)$, and .59 for Openness to Experience $(\mathrm{N}=5,333$, $\mathrm{k}=38$ ). Results showed that, although there was some construct overlap, self and observer ratings contain a large amount of unique variance.

\section{$\underline{\text { Practical Implications }}$}

The results of this study lend support to the suggestion that the Choices Questionnaire measures the construct Learning Agility, a construct that can identify individuals who would perform well in new jobs. This is vital due to the extremely dynamic economical and technological environment that most organizations compete in to prosper. These "learning agile" individuals eagerly look forward to new environments and opportunities to learn.

Applications of the Choices Questionnaire to Organizational selection and development are readably apparent. The Choices questionnaire can be used as a part of a succession planning system within an organization. However, because the Choices Questionnaire is essentially a multi-rater instrument, it will encounter the same difficulties that the 360 degree instruments face. That is, once employees find out that the Choices Questionnaire will be used to decide who will be promoted, their ratings may 
not be honest. Specifically, in this study coworkers completed the Choices

Questionnaire, and therefore office politics may greatly affect the validity of the ratings. Also, repeated use of this instrument by the same individuals may also affect the validity of the ratings. However, unlike in this study, perhaps a more valid and reliable source to complete the Choices Questionnaire would be the person's supervisor. Additionally, perhaps a Choices Questionnaire can be developed as a self-report measure. As a selfreport measure, the Choices Questionnaire may be used to select individuals into an organization. Lastly, an important use of this instrument would be for developmental purposes only. To use this as a tool to develop or train employees in the ability to welcome the opportunity to learn new things such as new jobs.

\section{$\underline{\text { Limitations }}$}

Several items may limit the generalizability of this study. First, this study consisted of law enforcement personnel, a fairly distinct segment of the general population. Secondly, this research was correlational and cross-sectional, thus casual inferences cannot be extracted from the results. Additionally, the motivation of this nonapplicant sample may have affected the results as well. Furthermore, the sample was not randomly selected.

Another limitation involved the interrater reliability of the 2 co-workers who completed the Choices Questionnaire. Interrater reliability depended on how well the coworkers new the person being rated. Specifically, for co-workers who knew the participant from "less than 1 month" to "More than 5 years" the ratings were weakly correlated at $(\mathrm{r}=.21)$. While co-workers who knew the person being rated for "More 
than 5 years", the ratings correlated much higher $(r=.65)$. This presents a reservation concerning the aggregation of the Learning Agility ratings during the analysis.

This study used supervisor ratings of both overall job performance and job promotability. These two ratings were highly correlated $(r=.76)$, and this brings to question weather or not the supervisor raters distinguished between past/current performance and promotability in a new position. Another viewpoint, and one possibly closer to the truth is that the supervisor raters based their promotability ratings on past/current performance. That is, if the subordinate currently being rated was performing well, then the supervisor determined that this individual was worthy of promotion. This points to the conclusion that Learning Agility in this sample predicts job performance and not necessarily future performance in a new job. However, as stated earlier in this paper, biodata research is based upon the link of past performance to future performance. Future research may better specify the criterion variable of promotability beyond just a single item.

Lastly, an important task of this study was to confirm the factor structure of Learning Agility. Confirming the four factors of Learning Agility strengthens the construct validity of this theory. The correlations between the four factors were extremely high. The correlations between the four factors ranged from $r=.80$ to $r=.90$. This indicates a high degree of multicollinearity, and supports a one factor model of Learning Agility. Furthermore, an exploratory factor analysis was conducted. Specifically, a principle components analysis with a varimax rotation was conducted which revealed the presence of one factor. All the items had factor loadings greater than .50 that loaded onto one factor. To further confirm the construct validity and to further 
test the supporting factor structure of Learning Agility, a confirmatory factor analysis was conducted. AMOS (Arbuckle, 1995) was used to carry out the analysis which resulted in several fit indices including, goodness-of-fit index (GFI), adjusted goodnessof-fit (AGFI), the root mean squared residual (RMR), and the root mean square error of approximation (RMSEA). Results of the four-factor model indicated the GFI (.31) and the AGFI (-.15) did not provide a good fit with the four factor model. A value of 1 indicates the best fit for both the GFI and AGFI fit indices. The RMR (.54) and the RMSEA (.90) also indicated a poor fit with the four factor model. A value of 0 indicates the best fit for the RMR and the RMSR fit indices. Indeed, all of the fit indices did not support the four factor model. Furthermore, a 1 factor model of Learning Agility was supported instead. The fit indices for the 1 factor model included the GFI (.94), the AGFI (.70), the RMR (.01), and the RMSEA (.24). Although, the factor structure did not hold up as theorized, and weakens the construct validity of the Learning Agility construct, this construct remains useful. Just as research has shown that assessment centers lack a clear construct validity (Schneider \& Schmitt, 1992), nevertheless, this does not hinder its valuable use within organizations.

\section{$\underline{\text { Future Research }}$}

Clearly future research can start by utilizing a different set of participants in order to exam the generalizability of this construct. Law enforcement personnel are trained to follow orders and standard operating procedures. Any deviation from the established norm is not tolerated. Since the co-workers in this study could only base their observations of the participant being rated by their work behavior, it is logical to surmise 
that behaviors portrayed by the Change Agility construct were not readily observable. This could also explain why, Learning Goal Orientation and Change Agility were weakly related to job performance.

Also, the construct validity of Learning Agility can be expanded to other variables in personnel research. Such variables as Locus of Control, Self-Monitoring, Self-Efficacy, and Self-Esteem can be examined to further explore how the Learning Agility construct fits into the personnel selection nomological net. Specifically, those individuals with an external Locus of Control may be lower on Learning Agility because these individuals seek out reasons for failure outside of their control, and thus would not learn from their poor performances or develop new skills to over come these failures. Additionally, high Self-Monitors know themselves well, and may be high on Learning Agility as well. Additionally, individuals low on Self-Efficacy may be hesitant to act on certain tasks for fear of failure, and thus would be low on Learning Agility because these individuals would not be open to new environments or challenges. However, individuals low on Self-Esteem may not expect to achieve much in new environments, thus they may not be fearful to try, and may be high on Learning Agility by the fact that they may learn from their new experiences. Indeed, more research with the above construct may further position Learning Agility within a nomological net.

Additionally, such personnel selection issues consisting of differential prediction, bias, and adverse impact, with the Choices Questionnaire are important to examine. These topics are important to consider in today's society that demands fairness in employment contexts. When employment selection systems do not equally result in passing scores for all demographic groups, society perceives this as unfair. In discussing 
these topics it is important to realize the difference between empirical questions and value judgements of fairness. Empirical research may find a certain personnel selection system to be valid for its purpose (i.e., through statistical methods), yet unfair (i.e., a value judgement based which groups pass or fail).

Differential prediction involves the use of a statistical technique (e.g, hierarchical regression) to determine if race group predicts performance on a selection device, but is not predictive for another race group. If there is differential prediction on a selection device, than this is selection device is said to be biased. However, a selection device can be unbiased, even though there are race group performance differences. To insure fairness in this situation, society has passed laws and legislation, such as the $80 \%$ rule that determines adverse impact.

Adverse impact occurs when the passing rate of a minority group does not reach a certain percentage of the passing rate of nonminority group on any type of employment selection system. The generally accepted rule of thumb is $80 \%$. This means that the passing rate of minority groups has to be $80 \%$ of the passing rate of nonminority groups. If this measure shows no adverse impact, then this would show additional value for organizations. Unfortunately, the sample that was used was predominately white, and male. Thus the above data would not provide reliable answers to the question of adverse impact if Learning Agility is used in performance selection. Future researchers should use a diverse sample to examine the above issues in relation to the Choices questionnaire. Additionally, as stated earlier, a self-report version of the Choices Questionnaire may offer better construct validity research opportunities (e.g., would not have to contend with 
self vs. other observations), and options for practical applications in personnel selection (e.g., uses for applicants).

$\underline{\text { Conclusion }}$

Learning Agility as measured by the Choices Questionnaire has shown a significantly strong relation to job performance. Additionally, this construct has shown it can predict over and beyond traditional selection variables (e.g., cognitive ability $\&$ personality) in predicting job promotability. Although more work is needed in order to establish the construct validity of this construct, Learning Agility can still add value by aiding organizations in promoting "learning agile" individuals who will perform well in new jobs. 
Table 1

Correlations and Descriptive Statistics Among all Variables

\begin{tabular}{|c|c|c|c|c|c|c|c|c|c|c|c|c|c|c|c|c|c|}
\hline Variables & $M$ & SD & 1 & 2 & 3 & 4 & 5 & 6 & 7 & 8 & 9 & 10 & 11 & 12 & 13 & 14 & 15 \\
\hline 1. Learning Agility & 263.3 & 71.47 & $(.99)$ & & & & & & & & & & & & & & \\
\hline 2. People Agility Factor & 98.25 & 24.88 & $.80^{\star \star}$ & $(.94)$ & & & & & & & & & & & & & \\
\hline 3. Mental Agility Factor & 68.8 & 19.53 & $.97^{\star \star}$ & $.87^{\star *}$ & $(.95)$ & & & & & & & & & & & & \\
\hline 4. Results Agility Factor & 61.22 & 16.05 & $.95^{\star *}$ & $.86^{\star \star}$ & $.90^{\star \star}$ & $(.94)$ & & & & & & & & & & & \\
\hline 5. Change Agility Factor & 36.2 & 12.18 & $.91^{\star \star}$ & $.80^{\star \star}$ & $.88^{\star \star}$ & $.83^{\star \star}$ & $(.91)$ & & & & & & & & & & \\
\hline 6. Cognitive Ability & 27.21 & 6.43 & .08 & .07 & .10 & .03 & .11 & $.81^{\mathrm{a}}$ & & & & & & & & & \\
\hline 7. Extraversion & 33.77 & 7.89 & -.01 & .04 & .02 & -.01 & .11 & -.08 & $(.90)$ & & & & & & & & \\
\hline 8. Agreeableness & 40.12 & 5.40 & .04 & .17 & .08 & .12 & .08 & -.03 & $.22^{*}$ & $(.84)$ & & & & & & & \\
\hline 9. Emotional Stability & 38.27 & 6.72 & -.02 & .08 & -.03 & .03 & -.06 & .09 & $.21^{*}$ & $19^{*}$ & $(.88)$ & & & & & & \\
\hline 10. Conscientiousness & 41.53 & 5.29 & -.06 & -.07 & -.01 & -.06 & -.06 & -.15 & .06 & -.04 & .19 & $(.84)$ & & & & & \\
\hline 11. Openness to Experience & 36.76 & 4.79 & .13 & .10 & $.21^{*}$ & .10 & $.23^{*}$ & .15 & $.30^{\star *}$ & .12 & .08 & $.20^{*}$ & $(.77)$ & & & & \\
\hline 12. Performance Goal Orientation & 40.11 & 7.11 & .17 & .09 & .18 & .11 & .08 & .03 & -.18 & -.17 & $-.28^{\star \star}$ & .09 & .03 & $(.75)$ & & & \\
\hline 13. Learning Goal Orientation & 47.89 & 4.54 & .07 & .09 & .12 & .12 & .13 & .13 & .01 & $.20^{\star}$ & .13 & .14 & $.30^{* \star}$ & -.04 & $(.77)$ & & \\
\hline 14. Overall Job Performance & 7.4 & 1.14 & $.37^{\star \star}$ & $.35^{\star \star}$ & $.24^{*}$ & $.29^{\star \star}$ & .16 & .14 & -.15 & .09 & .17 & -.07 & .07 & .01 & -.01 & $\mathrm{n} / \mathrm{a}$ & \\
\hline 15. Job Promotability & 4.23 & 1.03 & $.40^{* *}$ & $.38^{* *}$ & $.36^{*}$ & $.33^{\star *}$ & $.25^{*}$ & .10 & -.03 & -.01 & .10 & -.02 & .13 & .18 & .09 & $.76^{\star \star}$ & $\mathrm{n} / \mathrm{a}$ \\
\hline
\end{tabular}


Table 2

Factor Loadings for the IPIP measure

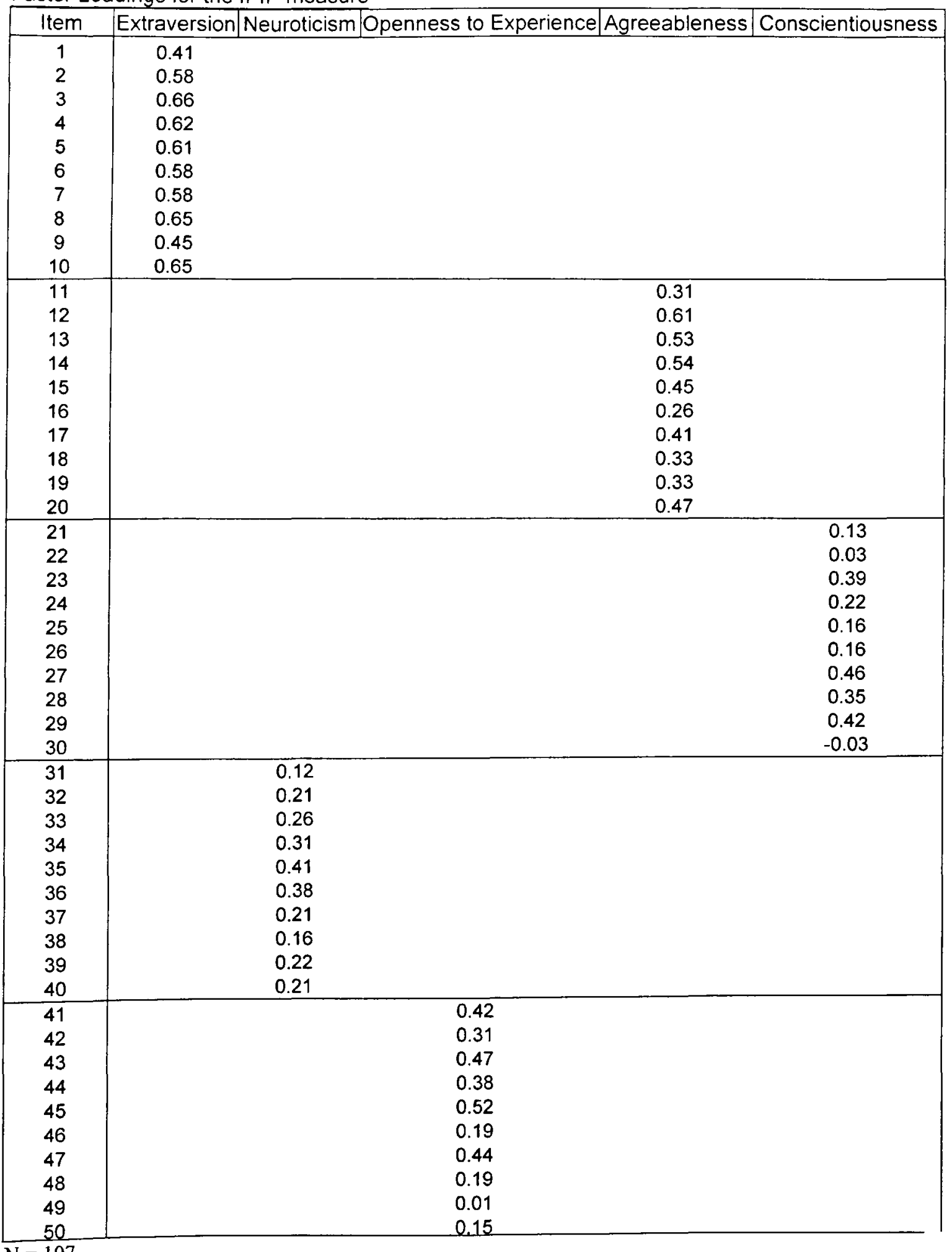

56 
Table 3

Factor Loadings for the Goal Orientation measure

\begin{tabular}{ccc}
\hline Item & $\begin{array}{c}\text { Performance } \\
\text { Goal Orientation }\end{array}$ & $\begin{array}{l}\text { Learning } \\
\text { Goal Orientation }\end{array}$ \\
\hline 1 & 0.72 & \\
2 & 0.22 & \\
3 & 0.75 & \\
4 & 0.66 & \\
5 & 0.62 & \\
6 & 0.42 & \\
7 & 0.78 & \\
8 & 0.65 & \\
9 & & 0.51 \\
10 & & 0.65 \\
11 & & 0.65 \\
12 & & 0.57 \\
13 & & 0.6 \\
14 & & 0.56 \\
15 & & 0.66 \\
16 & & 0.51 \\
\hline
\end{tabular}




\section{Table 4}

Hierarchical Regression Analysis for Learning Agility Predicting Supervisor Ratings of Job Performance

\begin{tabular}{|c|c|c|c|c|c|c|}
\hline & Predictor Entered & $\Delta \mathrm{F}$ & $d f$ & $\mathrm{R}^{2}$ & $\Delta \mathrm{R}^{2}$ & std. B \\
\hline & & \multicolumn{5}{|c|}{ Job Performance } \\
\hline Step 1: & Cognitive Ability & 2.06 & 1,105 & .019 & .019 & .06 \\
\hline \multirow[t]{5}{*}{ Step 2: } & Extraversion & 1.806 & 5,100 & .100 & .081 & -.22 \\
\hline & Conscientiousness & & & & & -.09 \\
\hline & Agreeableness & & & & & .07 \\
\hline & Openness to Experience & & & & & .09 \\
\hline & Emotional Stability & & & & & .21 \\
\hline Step 3: & Learning Agility & $7.489^{\star \star}$ & 1,99 & .164 & .063 & $.26^{\star \star}$ \\
\hline
\end{tabular}

${ }^{\star \star} p<.01 ; N=107$ 
Table 5

Hierarchical Regression Analysis for Learning Agility Predicting Supervisor Ratings of Job Promotability

\begin{tabular}{|c|c|c|c|c|c|c|}
\hline & Predictor Entered & $\Delta \mathrm{F}$ & $d f$ & $\mathrm{R}^{2}$ & $\Delta \mathrm{R}^{2}$ & std. B \\
\hline & & \multicolumn{5}{|c|}{ Job Promotability } \\
\hline Step 1: & Cognitive Ability & .998 & 1,105 & .009 & .009 & .04 \\
\hline \multirow[t]{5}{*}{ Step 2: } & Extraversion & .593 & 5,100 & .038 & .029 & -.07 \\
\hline & Conscientiousness & & & & & -.03 \\
\hline & Agreeableness & & & & & -.04 \\
\hline & Openness to Experience & & & & & .10 \\
\hline & Emotional Stability & & & & & .12 \\
\hline Step 3: & Learning Agility & $11.701^{\star \star}$ & 1,99 & .14 & .102 & $.32^{\star *}$ \\
\hline
\end{tabular}

$\star x<.01 ; N=107$ 
Table 6

Hierarchical Regression Analysis for Learning Agility Predicting Supervisor Ratings of the 11 Job Performance Dimensions

\begin{tabular}{|c|c|c|c|c|c|c|}
\hline & Predictor Entered & $\Delta \mathrm{F}$ & $\mathrm{df}$ & $\mathrm{R}^{2}$ & $\Delta \mathrm{R}^{2}$ & std. $\beta$ \\
\hline & & \multicolumn{5}{|c|}{11 Job Performance Dimensions } \\
\hline Step 1: & Cognitive Ability & 1.299 & 1,105 & .012 & .012 & .08 \\
\hline \multirow[t]{5}{*}{ Step 2: } & Extraversion & 1.342 & 5,100 & .074 & .062 & -.22 \\
\hline & Conscientiousness & & & & & .07 \\
\hline & Agreeableness & & & & & .11 \\
\hline & Openness to Experience & & & & & -.01 \\
\hline & Emotional Stability & & & & & .11 \\
\hline Step 3: & Learning Agility & $13.538^{* *}$ & 1,99 & .186 & .111 & $.34^{* *}$ \\
\hline
\end{tabular}




\section{LIST OF REFERENCES}

Anastasi, A., \& Urbina, S. (1997). Psychological testing. Upper Saddle River, NJ: Prentice Hall.

Atwater, L.E. (1992). Beyond cognitive ability: Improving the prediction of performance. Journal of Business and psychology, 7, 27- 44 .

Atwater, L.E., Ostroff, C., Yammarino, F.J., \& Fleenor, J.W. (1998). Self-other agreement: Does it really matter? Personnel Psychology, 51, 577-598.

Baldwin, T.T., Magjuka, R.J., \& Loher, B.T. (1991). The perils of participation: Effects of learner choice on motivation and learning. Personnel Psychology, 44, 51-66.

Baltes, P.B., Smith, J., \& Staudinger, U.M. (1992). Wisdom and successful aging. Sonderregger, Theo B., Nebraska symposium on motivation 1991: Psychology and Aging.

Barrick, M.R., \& Mount, M. K. (1991). The big five personality dimensions and job performance: A meta-analysis. Personnel Psychology, 44, 1-25.

Barrick, M.R., \& Mount, M. K. (1996). Effects of impression management and selfdeception on the predictive validity of personality constructs. Journal of Applied Psychology, 81, 261-272.

Becker, B. E., \& Huselid, M.A. (1992). The incentive effects of tournament compensation systems. Administrative Science Quarterly, 37, 336-350.

Bernardin, H.J., Cooke, D.K., \& Villanova, P. (2000). Conscientiousness and agreeableness as predictors of rating leniency. Journal of Applied Psychology, 85, 232234.

Bobko, P., \& Colella, A. (1994). Employee reactions to performance standards: A review and research propositions. Personnel Psychology, 47, 1-29.

Borman, W.C., Hanson, M., \& Hedge, J. (1997). Personnel selection. Annual Review of Psychology, 48, 299-337.

Bowers, C.A. (1999). Why culture rather than data should be understood as the basis of intelligence. In J. Kane's (eds.)Education, information, and transformation: Essays on learning and thinking. Upper saddle River, NJ: Prentice-Hall.

Button, S., Mathieu, J., \& Zajac, D. (1996). Goal orientation in organizational behavior research: A conceptual and empirical foundation. Organizational behavior and Human Decision processes, 67, 26-48. 
Caligiuri, P.M. (2000). The big five personality characteristics as predictors of expatriate's desire to terminate the assignment and supervisor rated performance. Personnel Psychology, 53, 67-88.

Carraher, T.N., Carraher, D., \& Shliemann, A.D. (1985). Mathematics in the streets and in schools. British Journal of Developmental Psychology, 3, 21-29.

Carroll, J.B. (1993). Human cognitive abilities: A survey of factor-analytic studies. New York: Cambridge University Press.

Carroll, J.B. (1997). Psychometrics, intelligence, and public perception. Intelligence, $\underline{24,25-52 .}$

Carroll, J.B. (1998). Human cognitive abilities: A critique. In J.J. Mcardle and R.W. Woodcock (eds.) Human cognitive abilities in theory and practice. Mahwah, NJ: Lawrence Erlbaum Associates.

Ceci, S.J. (1996). On intelligence: A bio-ecological treatise on intellectual development. Englewood Cliffs. NJ: PrenticeHall.

Ceci, S.J., \& liker, J. (1986). A day at the races: A study of IQ, expertise, and cognitive complexity. Journal of Experimental Psychology: General, 115, 255-266.

Ceci, S.J., \& liker, J. (1987). IQ and reasoning complexity: The role of experience. Journal of Experimental Psychology: General, 116, 304-306.

Chan, D. (1996). Criterion and construct validation of an assessment center. Journal of Occupational and Organizational Psychology, 69, 167-181.

Colquitt, J.A., \& Simmering, M. J. (1998). Conscientiousness, goal orientation, and motivation to learn during the learning process: A longitudinal study. Journal of Applied Psychology, 83, 654-665.

Cornelius, S.W., \& Caspi, A. (1987). Everyday problem solving in adulthood and old age. Psychology and Aging, 2, 144-153.

Costa, P.T., Jr., \& McCrae, R.R. (1995). Solid ground in the wetlands of personality: A reply to Block. Psychological Bulletin, 117, 216-220.

Denny, N.W., \& Palmer, A.M. (1981). Adult age differences on traditional and practical problem-solving measures. Journal of Gerontology, 36, 323-328.

Digman, R. (1990). Personality structure: Emergence of the five-factor model. Annual Review of Psychology, 41, 417-440. 
Dweck, C.S. (1986). Motivational processes affecting learning. American Psychologist, 41, 1040-1048.

Dweck, C.S., \& Legget, E.L. (1988). A social-cognitive approach to motivation and achievement. Journal of Personality and Social Psychology, 54, 5-12.

Eichinger, R.W. \& Lombardo, M.M. (1997). High potentials as high learners. Human $\underline{\text { Resource Management Journal, }}$

Elliott, E.S., \& Dweck, C.S. (1988). Goals: An approach to motivation and achievement. Journal of Personality and Social Psychology, 54, 5-12.

Eysenck, H.J. (1998). Intelligence: A new look. Transaction Publishers. New Brunswick: New Jersey.

Fisher, C.D. (1986). Organizational socialization: An integrative review. In K. Rowland \& G. Ferris (Eds.) Research in personnel and human resources management, 4, 101-145, Grennwich, CT: JAI Press.

Fiedler, F.E. \& Link, T.G. (1994). Leader intelligence, interpersonal stress, and task performance. Sternberg, R.J. \& Wagner, R.K. Mind in context: Interactionist

Gardner, H. (1983). Frames of mind: The theory of multiple intelligences. New York: Basic Books.

Gardner, H. (1993). Multiple intelligences: The theory of multiple intelligences. New York: Basic Books.

Goleman, D. (1995). Emotional intelligence. New York: Bantam Books.

Goldberg, L.R. (1990). An alternative "description of personality": The big five factor structure. Journal of Personality and Social Psychology, 59, 1216-1229.

Goldberg, L.R. (2000). The development of five-factor domain scales from the IPIP item pool. Internet web site.

Harris, M., \& Schaubroeck, J. (1988). A meta-analysis of self-supervisor, self-peer, and peer-supervisor ratings. Personnel Psychology, 41, 43-61.

Hoffman, R.R. (1992). The psychology of expertise: Cognitive research and empirical AI/. New York, NY: Springer-Verlag.

Hollander, E.P. (1965). Validity of peer nominations in predicting a distant performance criterion. Journal of Applied Psychology, 49, 434-438. 
Hogan, R., Hogan, J., \& Roberts, B.W. (1996). Personality measurement and employment decisions. American Psychologist, 51, 469-477.

Hollenbeck, J.R., \& Klein, H.J. (1987). Goal commitment and the goal-setting process: Problems, prospects, and proposals for future research. Journal of Applied Psychology, 72, 204-211.

Horn, J.L. (1982). The theory of fluid and crystallized intelligence in relation to concepts of cognitive psychology and aging in adulthood. In F.I.M. Craik and A. Trehub (eds.). Aging and cognition processes (pp. 237-278) New York: Plenum.

Horn, J.L. (1994). The theory of fluid and crystallized intelligence. In R.J. Sternberg (Ed.), Encyclopedia of human intelligence (pp. 443-451). New York: Macmillan.

Hunter, J.E. (1986). Cognitive ability, cognitive aptitudes, job knowledge, and job performance. Journal of Vocational Behavior, 29, 340-362.

Hunter, J.E., \& Hunter, R.F. (1984). Validity and utility of alternate predictors of job performance. Psychological Bulletin, 96, 72-98.

Jensen, A.R. (1998). The g factor: The science of mental ability. Westport, CT: Praeger.

Jensen, A.R. (1986). Major contributions g: Artifact or Reality? Journal of Vocational behavior, 29, 301-331.

Jensen, A. R. (1980). Bias in mental testing. New York: Free Press.

Judge, T.A., \& Bono, J.E. (2000). Five-factor model of personality and transformational leadership. Journal of Applied Psychology, 85, 751-765.

Judge, T.A., Higgins, C.A., Thorsen, C.J., \& Barrick, M.R. (1999). The big five personality traits, general mental ability, and career success across the life span. Personnel Psychology, 52, 621-653.

Judge, T.A., Martocchio, J.J., \& Thoresen, C.J. (1997). Five-factor model of personality and employee absence. Journal of Applied Psychology, 82, 745-755.

Lambert, R.A. (1993). The structure of organizational incentives. Administrative Science Quarterly, 38, 438-461.

Lave, M. (1988). Cognition in practice. New York: Cambridge University Press.

Locke, E.A. (1968). Toward a theory of task motivation and incentives. Organizational Behavior and Human Performance, 3, 157-189. 
Locke, E.A., Chah, D-O., Harrison, S., \& Lustgarten, N. (1989). Separating the effects of goal from goal level. Organizational Behavior and Human Decision Processes, 43, 270-287.

Locke, E.A., Latham, G.P., \& Erez, M. (1988). The determinants of goal commitment. Academy of Management Review, 13, 23-39.

Love, K.G. (1981). Comparison of peer assessment methods: Reliability, validity, friendship bias, and user reaction. Journal of Applied Psychology, 66,451-457.

Maccoby, M. (2000). Narcissistic leaders: The incredible pros, the inevitable cons. Harvard Business Review, 78, 69-77.

Marlowe, Jr., H.A. (1986). Social intelligence: Evidence for multidimensionality and construct independence. Journal of Educational Psychology, 78, 52-58.

Martocchio, J.J., \& Judge, T.A. (1997). Relationship between conscientiousness and learning in employee training: Mediating influences of self-deception and self-efficacy. Journal of Applied Psychology, 82, 764-773.

Martocchio, J.J., \& Webster, J. (1992). Effects of feedback and cognitive playfulness on performance in microcomputer software training. Personnel Psychology, 45, 553-578.

Mayer, J.D., Dipaolo, M., \& Salovey, P. (1990). Perceiving the affective content in ambiguous stimuli: A component of emotional intelligence. Journal of Personality Assessment, 50, 772-781.

Mayer, J.D., \& Salovey, P. (1993). The intelligence of emotional intelligence. Intelligence, 17, 433-442.

Mayfield, E.C. (1970). Management selection: Buddy nominations revisited. Personnel Psychology, 23, 377-391.

McCall, Jr., M.W., Lombardo, M.M., \& Morrison, A.M. (1988). The lessons of experience: How successful executives develop on the job. New York, NY: Lexington Books.

McCauley, C.D., Ruderman, M.N., Ohlott, P.J., \& Morrow, J.E. (1994). Assessing the developmental components of managerial jobs. Journal of Applied Psychology, 79, 544560.

McCrae, R.R., \& Costa, Jr., P.T. (1997). Personality trait structure as a human universal. American Psychologist, 52, 509-516. 
McDaniel, D., \& Frei, T. (1994). Validity of customer service measures in personnel selection: A meta-analysis. Presented at the $9^{\text {th }}$ annual meeting of the Society for Industrial and Organizational Psychology, Nashville, TN.

McKenna, J. (1992). Welcome Aboard. Industry Week. November, 6, 34.

Mount, M.K., \& Barrick, M.R. (1998). Five reasons why the "Big Five" article has been frequently cited. Personnel Psychology, 51, 849-857.

Mount, M.K., Barrick, M.R., \& Stewart, G.L. (1998). Five-Factor model of personality and performance in jobs involving interpersonal interactions. Human Performance, 11, 145-165.

Murphy, K.R. (1996). Individual differences and behavior in organizations: Much more than "g". In Individual differences and behavior in organizations. San Francisco: Josey-bass.

Neisser, U., Boodoo, G., Bouchard, Jr., T.J., Brody, N., Ceci, S.J., Halpern, D.F., Loehlin, J.C., Perloff, R., Sternberg, R.J., \& Urbina, S. (1996). Intelligence: Knowns and Unknowns. American Psychologist, 51, 77-101.

Nevo, B., \& Chawarski, M.C. (1997). Individual differences in practical intelligence and success in immigration. Intelligence, 25, 83-92.

Okagaki, J., \& Sternberg, R.J. (1993). Parental beliefs and children's school performance. Child Development, 64,36-56.

Ones, D.S., Viswesvaran, C., \& Schmidt, F.L. (1993). Comprehensive meta-analysis of integrity test validities: Findings and implications for personnel selection and theories of job performance. Journal of Applied Psychology Monograph, 78, 679-703.

Perkins, D.N. (1995). Outsmarting IQ: The emerging science of learnable intelligence. New York, NY: Free Press.

Pervin, L.A. (1980). Personality theory and assessment. New York: Wiley.

Phillips, J.M., \& Gully, S.M. (1997). Role of goal orientation, ability, need for achievement, and locus of control in the self-efficacy and goal-setting process. Journal of Applied Psychology, 82, 792-802.

Pinefield, L.T. (1995). The operation of internal labor markets: Staffing practices and vacancy chains. New York: Plenum Press.

Pulakos, E.D., Arad, S., Donovan, M.A., \& Plamondon, K.E. (2000). Adaptability in the workplace: Development of a taxonomy of Adaptive performance. Journal of Applied Psychology, 85, 612-624. 
Pulley, B. (2000). The High cost of crankiness. Forbes, April, 58-60.

Ree, M.J., \& Earles, J.A. (1992). Intelligence is the best predictor of job performance. Current Directions in Psychological Science, 1, 86-89.

Ree, M.J., Earles, J.A., \& Teachout, M.S. (1994). Predicting job performance: Not much more than g. Journal of Applied Psychology, 79, 518-524.

Ree, M.J., Carretta, T.R., \& Teachout, M.S. (1995). Role of ability and prior job knowledge in complex training performance. Journal of Applied Psychology, 80, 721730 .

Salgado, J.F. (1997). The five-factor model of personality and job performance in the European Community. Journal of Applied Psychology, 82, 30-43.

Schneider, J. \& Schmitt, N. (1992). An exercise design approach to understanding assessment center dimension and exercise constructs. Journal of Applied Psychology, 77, 298-308.

Schmidt, F.L., \& Hunter, J.E. (1998). Measurable personnel characteristics: Stability, variability, and validity for predicting future job performance. In M. Kleinmann \& B. Strauss (Eds.). Instruments for potential assessment and personnel development. Gottingen, Germany: Hogrefe.

Schmidt, F.L., \& Hunter, J.E. (1998). The validity and utility of selection methods in personnel psychology: Practical and theoretical implications of 85 years of research findings. Psychological Bulletin, 124, 262-274.

Sloan, E.B. (2001). Identifying and developing high potential talent: A succession management methodology. The Industrial-Organizational Psychologist, 38, $84-90$.

Sternberg, R.J. (1985). Beyond IQ: A triarchic theory of human intelligence. New York, NY: Cambridge University Press.

Sternberg, R.J. (1986). A framework for understanding conceptions of intelligence. In R. Sternberg, \& D. Detterman's (Eds.) What is intelligence? Contemporary viewpoints on its nature and definitions. Norwood, NJ: Albex.

Sternberg, R.J. (1988). Mental self-government: A theory of intellectual styles and their development. Human Development, 31, 197-224.

Sternberg, R.J. (1997). The concept of intelligence and its role in lifelong learning and success. American Psychologist, 52, 1030-1037. 
Sternberg, R.J., \& Ruzgis, P. (1994). Personality and intelligence. New York, NY: Cambridge University Press.

Sternberg, R.J., Wagner, R.K., Williams, W.M., \& Horvath, J.A. (1995). Testing Common Sense. American Psychologist, 50, 912-927.

Tabachnick, B.G., \& Fidell, L.S. (2001). Using Multivariate Statistics $\left(4^{\text {th }}\right.$ Eds.). Needham Heights, MA: Allyn \& Bacon.

Vandewalle, D.M. (1996). Are our students trying to prove or improve their ability? Development and validation of an instrument to measure academic goal orientation. Paper presented at the $56^{\text {th }}$ annual meeting of the Academy of Management, Cincinnati, Ohio.

Vandewalle, D.M. (1997). Development and validation of a work domain goal orientation instrument. Educational and Psychological Measurement, 8, 995-1015.

Vandewalle, D., \& Cummings, L.L. (1997). A test of the influence of goal orientation on the feedback-seeking process. Journal of Applied Psychology, 82, 390-400.

Vandewalle, D., Brown, S.P., Cron, W.L., \& Slocum, J.W. (1999). The influence of goal orientation and self-regulation tactics on sales performance: A longitudinal field test. Journal of Applied Psychology, 84, 249-259.

Vinchur, A.J., Schippmann, J.S., Switzer III, F.S. (1998). A meta-analytic review of predictors of job performance for salespeople. Journal of Applied Psychology, 83, 586597.

Wagner, R.K. (1991). Managerial problem-solving. In R.J. Sternberg \& P. Finch (Eds.). Complex problem solving: Principles and mechanisms (pp. 159-183). New York: Cambridge university Press.

Wagner, R.K. (1997). Intelligence, training, and employment. American Psychologist, 52, 1059-1069.

Wagner, R.K., \& Sternberg, R.J. (1985). Practical intelligence in real-world pursuits: The role of tacit knowledge. Journal of Personality and Social psychology, 49, 436-458.

Wagner, R.K., \& Sternberg, R.J. (1990). Street smarts. In K.E. Clark \& M.B. Clark (Eds.), Measures of Leadership (pp.493-504). West Orange, N.J.: Leadership Library of America.

Weitz, J. (1958). Selecting supervisors with peer ratings. Personnel Psychology, 11, 25-35. 
Williams, S.B., \& Leavitt, H.S. (1947). Group opinions as a predictor of military leadership. Journal of Consulting Psychology, 11, 283-291. 


\section{APPENDIX A \\ SUPERVISOR \\ General Instructions}

Thank you for participating in this study. The contact person within your department has given you several sets of packets that are each bounded by a rubber band. Each bounded set contains 4 packages named: participant, coworker 1, coworker 2 and supervisor. Members from your command will either be a participant, or either one of the two coworkers in this study, and you of course will be the supervisor. Please inquire if any members of your command would be willing to participate in this research study. Next follow the below instructions.

You will be coordinating and dispersing the set of packages. This involves keeping track of who completes what packet. Attached you will find a Participant Assignment Sheet.

\section{Instructions:}

1. Complete the Participant Assignment Sheet. Print your name in the space for Supervisor, print a subordinate name in the Participant column, a subordinate in the Coworker 1 column, and another subordinate in the coworker 2 column. Your subordinates can only be a participant, a coworker 1, or a coworker 2. Please make sure that each subordinate, coworker 1 , coworker 2 triad have as much similar attributes such as years of experience. I realize that it is not possible always, but please try to match your subordinates within each triad.

2. Once the Participant Assignment Sheet is complete, unbound the sets of packets and label each packet with the appropriate name according to your names listed on the Participant Assignment Sheet. This is critical!

\section{For example:}

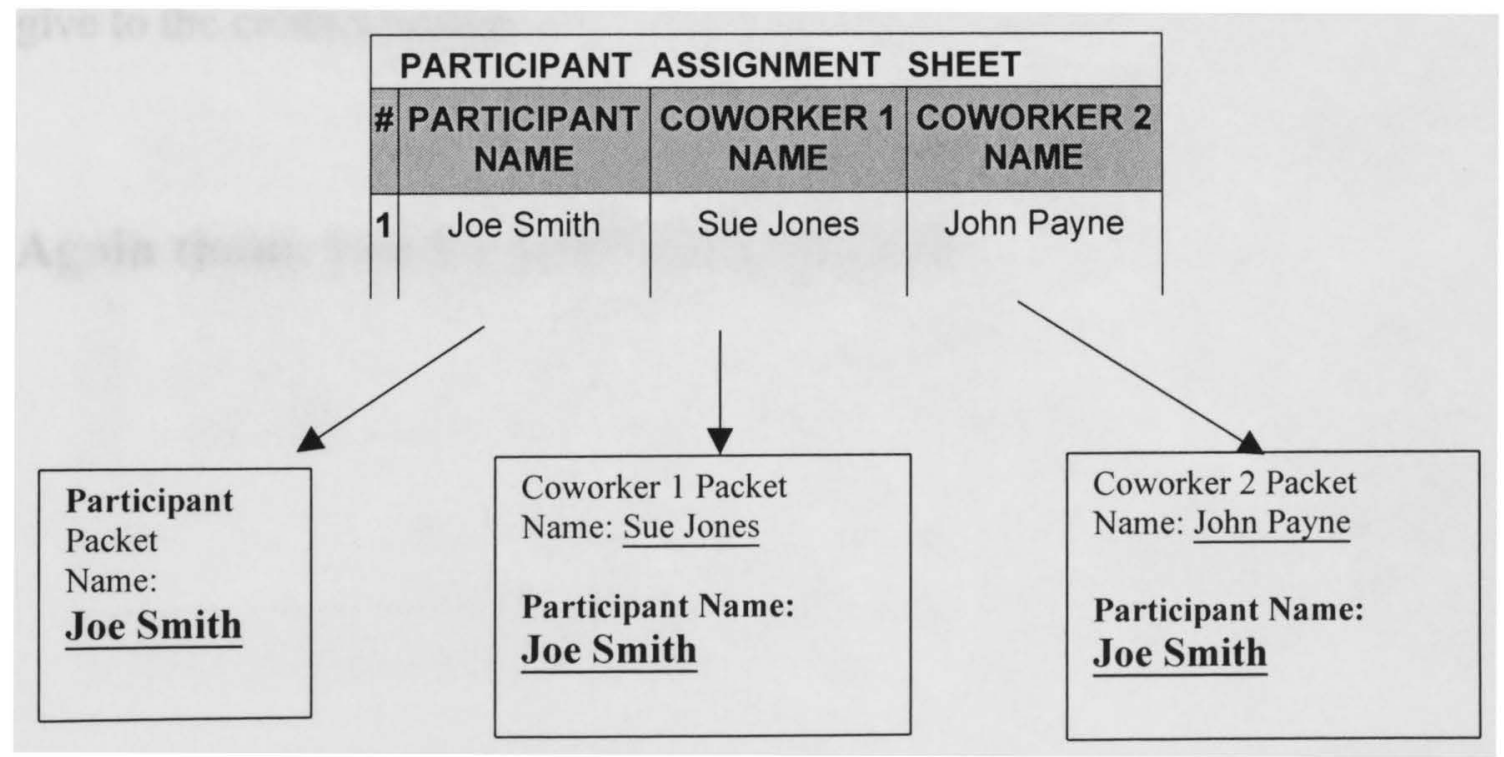

3. Once all of the packets are labeled with the appropriate names distribute them to the selected personnel.

4. Give the completed packages back to the designated contact person in your department.

\section{Again thank you for your participation!}




\section{SUPERVISOR}

Thank you for participating in this study. This packet contains an Informed Consent form, a Background Information sheet and a job performance evaluation sheet.

The next page contains an Informed Consent Form that must be read and signed before you complete the background Information sheet and the job performance evaluation sheet. Please note that you are completing one job performance evaluation for each "Participant" (and not for any co-worker).

CRITICAL: Please fill this questionnaire out based on the person's name listed next to

"Participant 1" on the package cover.

After completing the Informed Consent Form, the background Information sheet and the job performance evaluation sheet, place all the items into the security envelope. Give this security envelope back to the designated contact person in your department.

Please also collect the other finished packets from your subordinates, and give to the contact person.

\section{Again thank you for your participation!}

\section{Please turn the page.}




\section{Job Performance Evaluation}

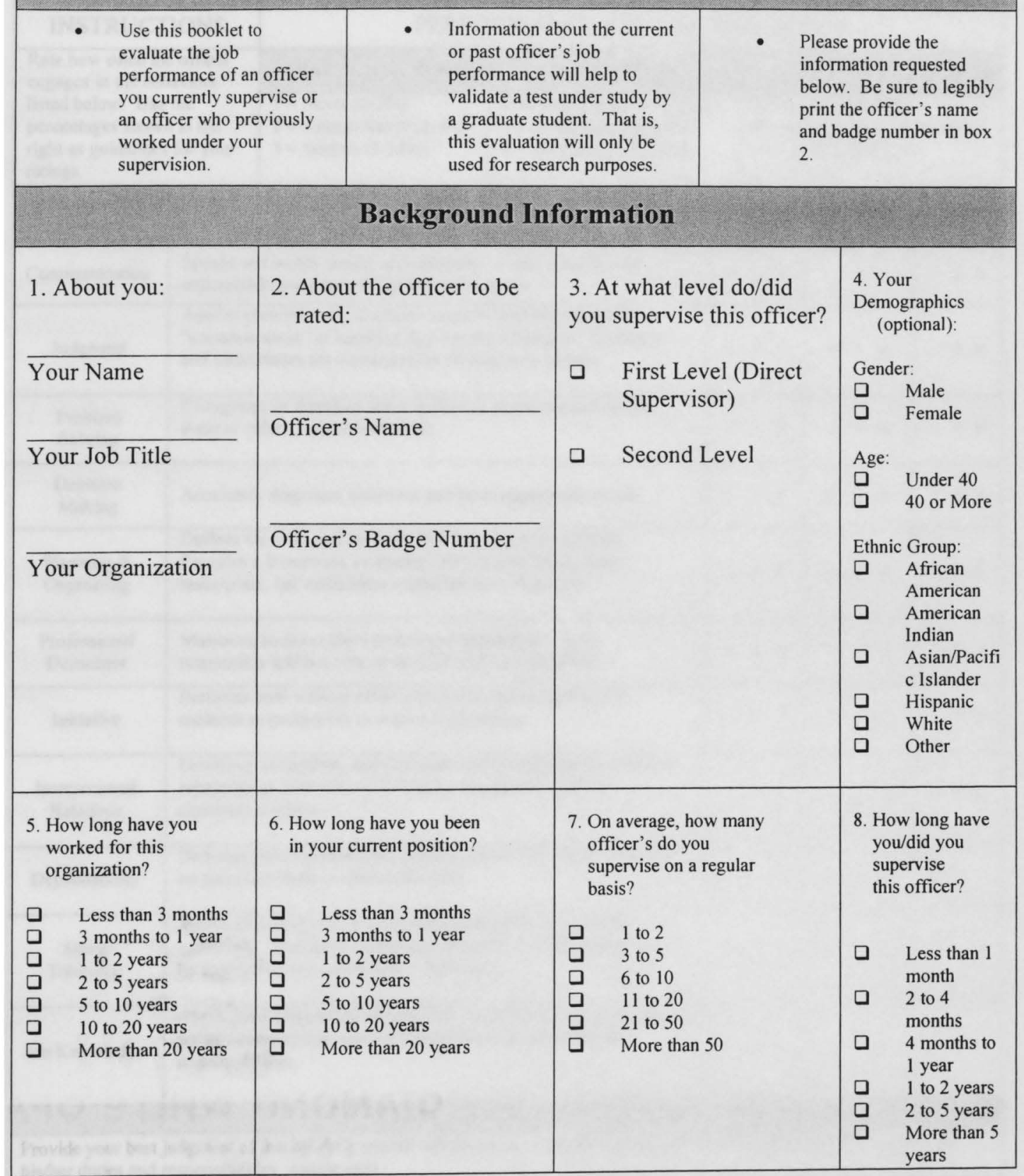




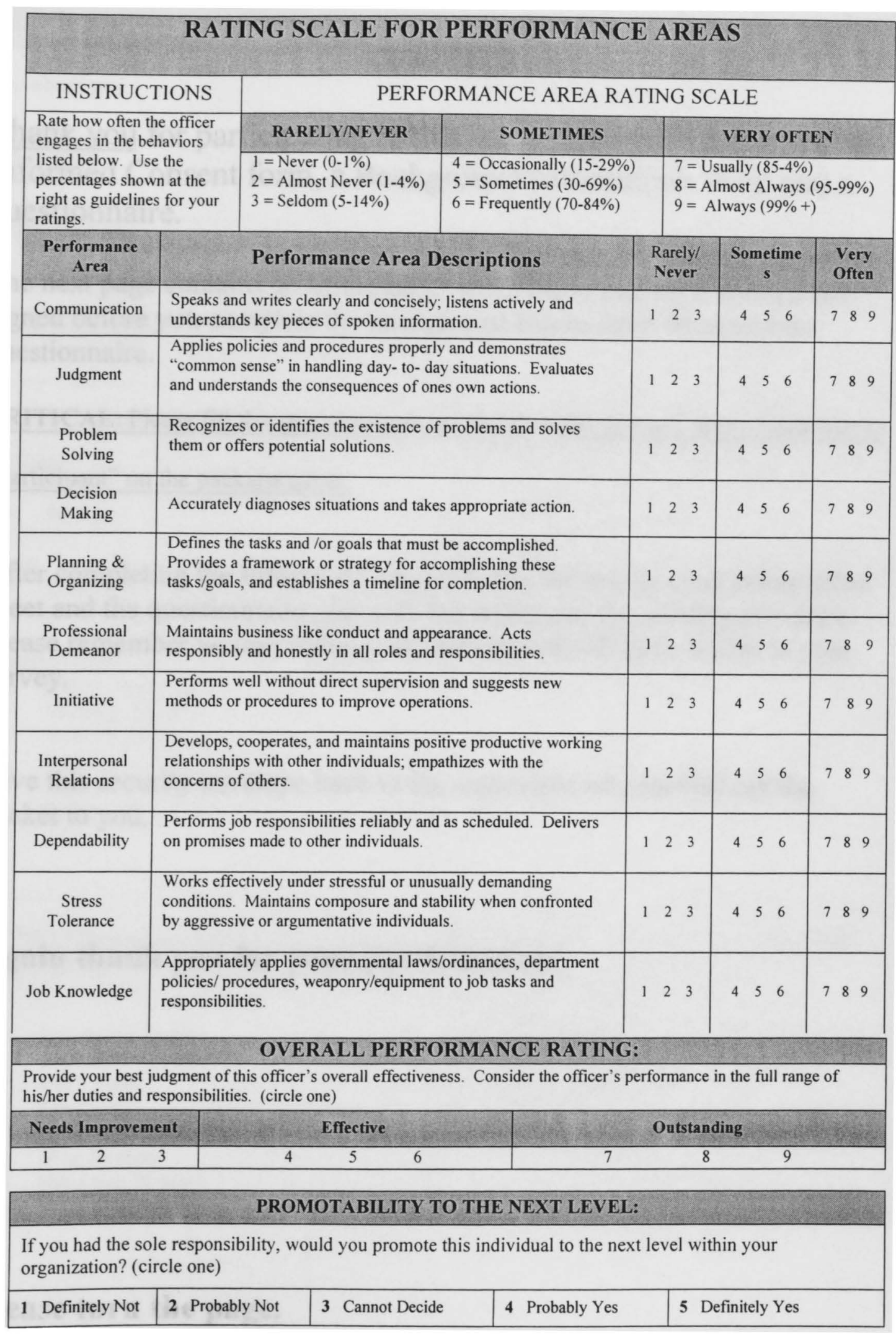




\section{APPENDIX B}

COWORKER 1

Thank you for participating in this study. This packet contains an Informed Consent form, a Background Information sheet and a questionnaire.

The next page contains an Informed Consent Form that must be read and signed before you complete the background Information sheet and the questionnaire.

CRITICAL: Please fill this questionnaire out based on the person's name listed next to

"Participant" on the package cover.

After completing the Informed Consent Form, the background Information sheet and the questionnaire, place all the items into the security envelope. Please remember no one within your department will have access to your survey.

Give this security envelope back to the supervisor who handed out the packet to you.

\section{Again thank you for your participation!}

\section{Please turn the page.}




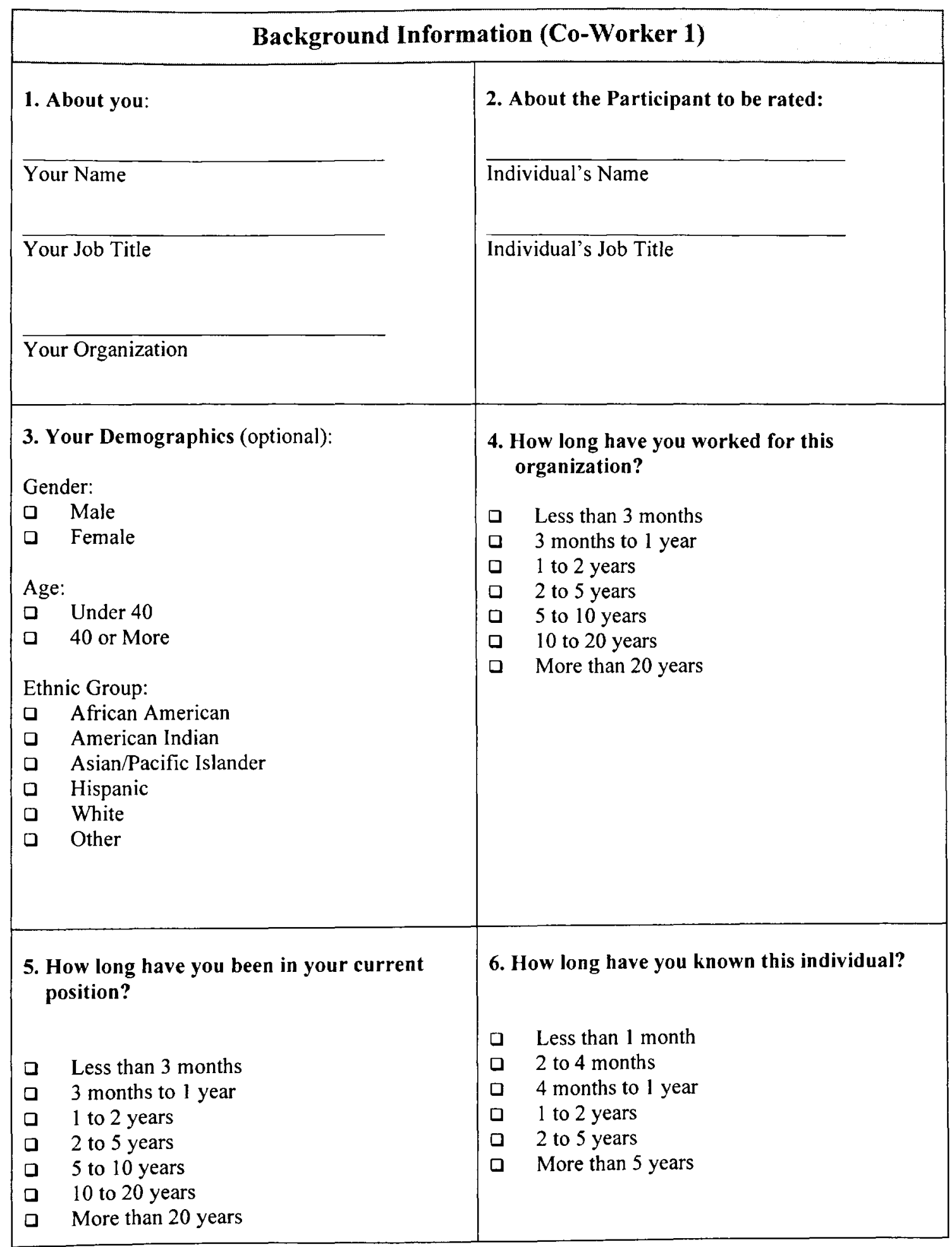


Co-Worker 1

Questionnaire

\section{Instructions for the Questionnaire}

Please follow the directions on the following pages carefully.

Please remember to fill this questionnaire out based on the

person's name listed next to "Participant" on the package cover.

Please turn the page to start the Questionnaire. 


\section{APPENDIX C}

CO-WORKER 2

Thank you for participating in this study. This packet contains an Informed Consent form, a Background Information sheet and a questionnaire.

The next page contains an Informed Consent Form that must be read and signed before you complete the background Information sheet and the questionnaire.

CRITICAL: Please fill this questionnaire out based on the person's name listed next to "Participant" on the package cover.

After completing the Informed Consent Form, the background Information sheet and the questionnaire, place all the items into the security envelope. Please remember no one within your department will have access to your survey.

Give this security envelope back to the supervisor who handed out the packet to you.

\section{Again thank you for your participation!}

\section{Please turn the page.}




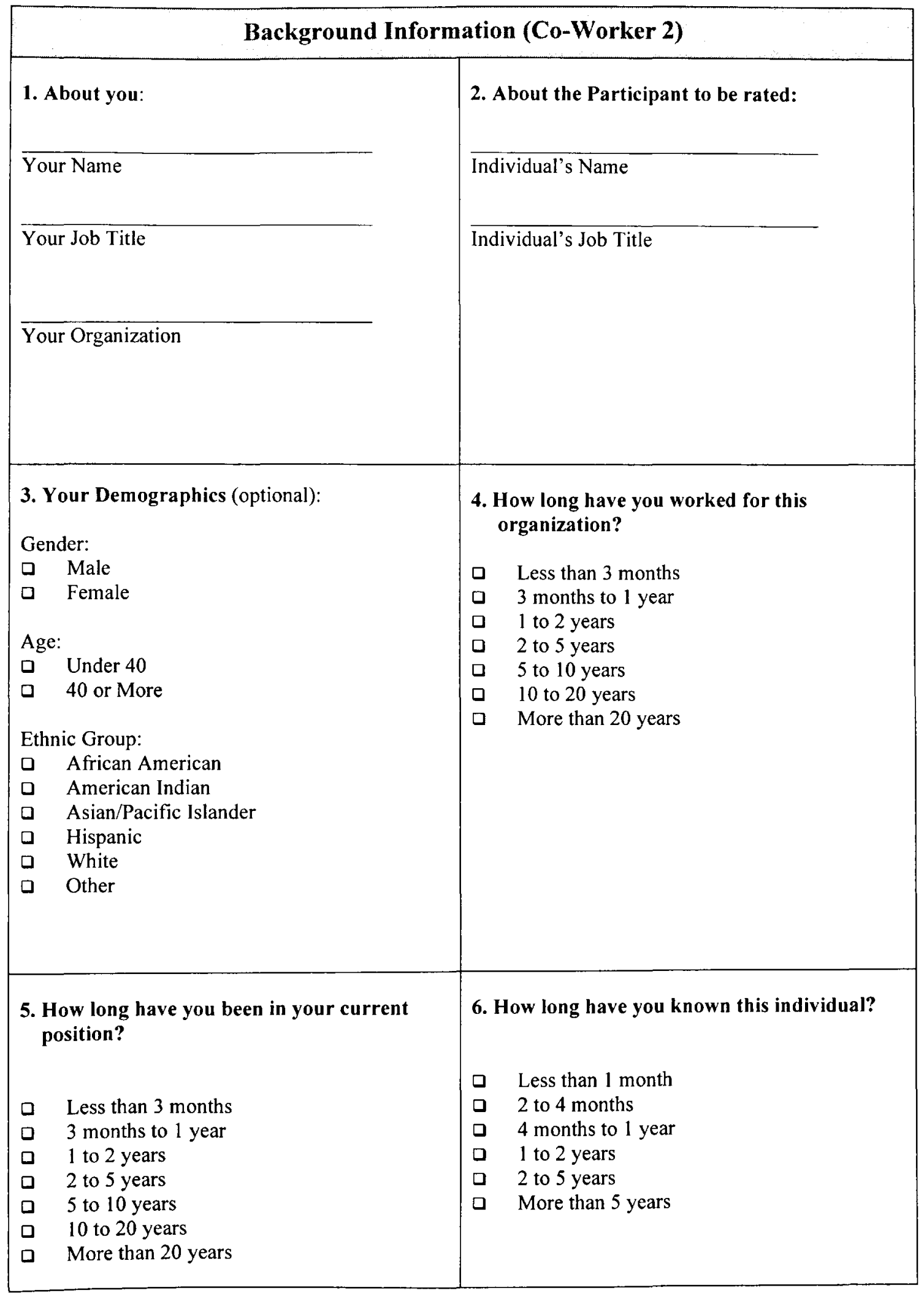




\section{Co-Worker 2}

Questionnaire

Instructions for the Questionnaire

Please follow the directions on the following pages carefully.

Please remember to fill this questionnaire out based on the

person's name listed next to "Participant" on the package cover.

Please turn the page to start the Questionnaire. 


\section{APPENDIX D}

PARTICIPANT

Thank you for participating in this study. This packet contains an Informed Consent form, a Background Information sheet and 3 questionnaires.

The next page contains an Informed Consent Form that must be read and signed before you complete the background Information sheet and the 3 questionnaires.

After completing the Informed Consent Form, the background Information sheet and the 3 questionnaires, place all the items into the security tamper evident envelope. Please remember no one within your department will have access to your survey.

Give this security envelope back to the supervisor who handed out the packet to you.

\section{Again thank you for your participation!}

\section{Please turn the page.}




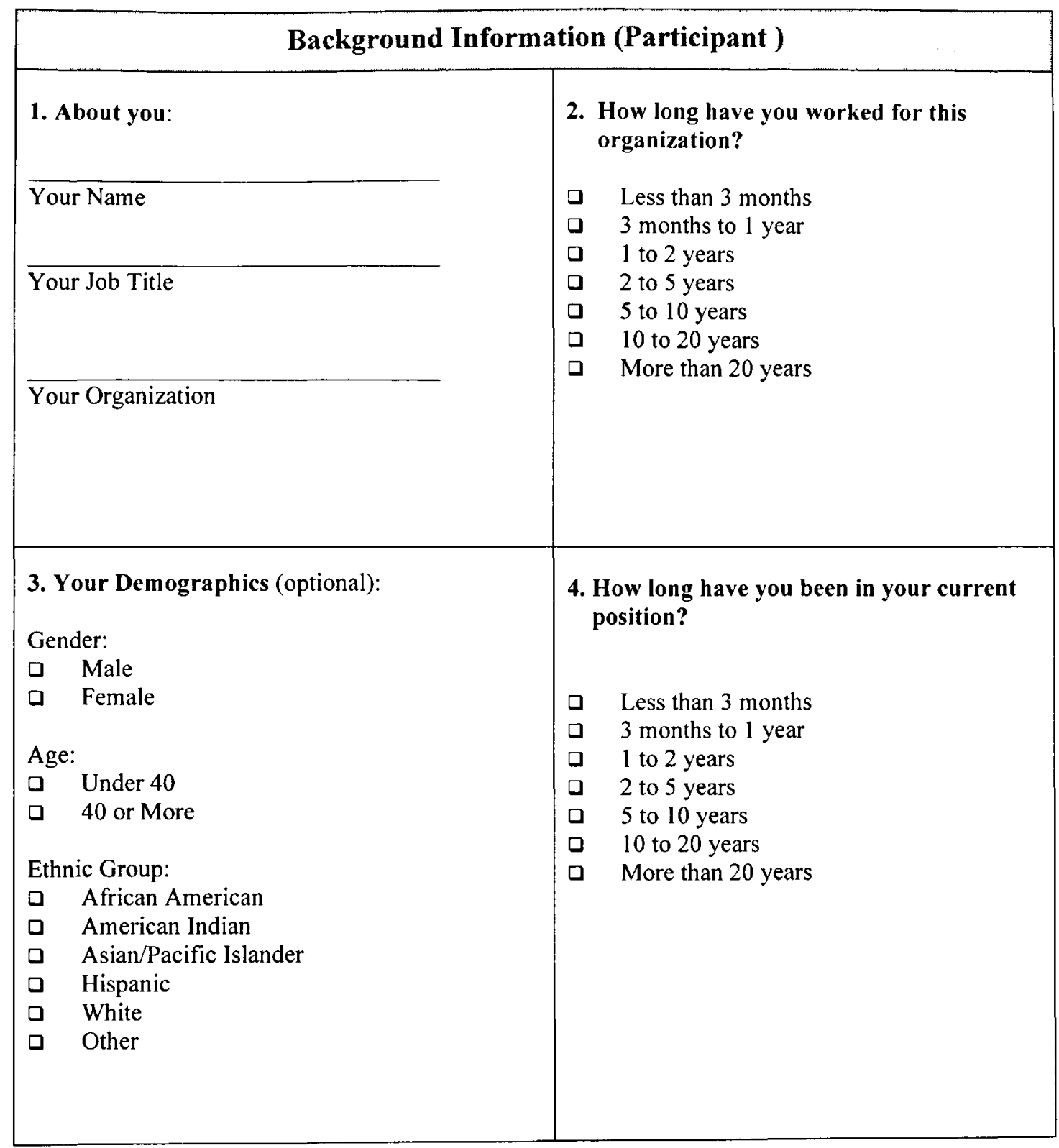




\section{Questionnaire 1}

\section{Instructions for Questionnaire 1}

On the following pages, there are phrases describing people's behaviors. Please use the rating scale below to describe how accurately each statement describes you. Describe yourself as you generally are now, not as you wish to be in the future. Describe yourself as you honestly see yourself, in relation to other people you know of the same sex as you are, and roughly your same age. So that you can describe yourself in an honest manner, your responses will be kept in absolute confidence. Please read each statement carefully, and then fill in the bubble that corresponds to the response option on the scale.

\section{Response Options}

1: Very Inaccurate

2: Moderately Inaccurate

3: Neither Inaccurate nor Accurate

4: Moderately Accurate

5: Very Accurate

\section{Please turn the page to start Questionnaire 1.}




\section{Questionnaire 2}

\section{Instructions for Questionnaire 2}

On the following pages, there are phrases describing people's behaviors. Please use the rating scale below to describe if you agree or disagree with each statement. Describe yourself as you generally are now, not as you wish to be in the future. Describe yourself as you honestly see yourself, in relation to other people you know of the same sex as you are, and roughly your same age. So that you can describe yourself in an honest manner, your responses will be kept in absolute confidence. Please read each statement carefully, and then fill in the bubble that corresponds to the response option on the scale.

\section{Response Options}
1: Strongly disagree
2: Disagree
3: Slightly disagree
4: Neither agree or disagree
5: Slightly agree
6: Agree
7: Strongly agree

Please turn the page to start Questionnaire 2. 


\section{Questionnaire 3}

Instructions for Questionnaire 3

Please follow the directions on the following pages carefully.

Please turn the page to start Questionnaire 3. 


\section{APPENDIX E}

\section{Informed Consent Form}

"Assessing the Construct Validity of a Measure of Learning Agility"

I freely and voluntarily consent to be a participant in the research project entitled "Assessing the Construct Validity of a Measure of Learning Agility" to be conducted at various organizations located across the United States during the Summer and Fall of 2000 with James Connolly as Principal Investigator and Dr. Chockalingam Viswesvaran as Faculty Supervisor.

I understand that the purpose of this research is to examine the theory of Learning Agility to predict work behavior. I understand I am one of 700 participants who are taking part in this research.

I understand that the research procedures will be as follows: Participants will respond to commonly used personality and ability questionnaires. Upon the completion of these questionnaires, the participants will be sent an information sheet providing a short explanation of the study and a word of thanks for participating in this research.

I understand that there are no known risks involved in my participation in this study. I understand that some of the participants will have their work behavior rated by their respective supervisors and that these results will be used for research purposes only. I understand that my response will be kept confidential. All responses will be identified by my full name, and my individual responses will not be revealed to anyone without my express permission.

I understand that I may withdraw my consent and discontinue participation in this research project at any time with no negative consequences.

I understand that if I desire further information about this research I should contact James Connolly at jconnoll@mdcc.edu or Dr. Chockalingam Viswesvaran at vish@fiu.edu.

I have read and I understand the above.

Participants Signature

Date

Participant's Name (Please Print) 


\section{Explanation}

\section{Assessing the Construct validity of a measure of Learning Agility James J. Connolly \\ Florida International University}

The title of this study does seem wordy, but don't worry, I'll try to cut through the jargon. Basically I'm trying to see if the questionnaire on "Learning Agility" measures what it is supposed to measure. It's kind of like trying to see if a yard-stick actually measures three feet. If the yard-stick does measure three feet, then you could say that the yard-stick is a valid measure of three feet. In this case the "Learning Agility" questionnaire (or measure), is supposed to see if certain people can perform and learn a new job quicker than other people. Learning Agility is also called a construct, that is, someone constructed it, to describe certain characteristics of people. Examples of other more familiar constructs include intelligence (or cognitive ability) and personality. In fact Cognitive ability and personality are two well-established constructs used in personnel selection for predicting job performance. However, the pursuit of finding more valid predictors of job performance is an unending process. That is why I'm looking at the construct called "Learning Agility", to see if it can help predict who will be able to perform and learn a new job quickly, then this would be valuable information for employers. Also, maybe this new information can help people understand themselves better, and help them learn.

I thank you for your help in this study. If you would like to know more about this topic, please feel free to contact me. My e-mail address is: jconno01@fiu.edu. 


\section{APPENDIX F}

\section{Goal Orientation Scale}

\begin{tabular}{|c|c|c|c|}
\hline & Item & Mean & $\begin{array}{l}\text { Standard } \\
\text { Deviation }\end{array}$ \\
\hline 1 & I prefer to do things that I can do well rather than things that I do poorly. & 5.58 & 1.31 \\
\hline 2 & $\begin{array}{l}\text { I'm happiest at work when I perform tasks on which I know that } \\
\text { won't make any errors. }\end{array}$ & 4.55 & 1.61 \\
\hline 3 & The things I enjoy the most are the things I do the best. & 4.94 & 1.68 \\
\hline 4 & $\begin{array}{l}\text { The opinions others have about how well I can do certain things } \\
\text { are important to me. }\end{array}$ & 5.26 & 1.42 \\
\hline 5 & I feel smart when I do something without making any mistakes. & 5.09 & 1.35 \\
\hline 6 & $\begin{array}{l}\text { I like to be fairly confident that I can successfully perform a task } \\
\text { before I attempt it. }\end{array}$ & 4.76 & 1.52 \\
\hline 7 & I like to work on tasks that I have done well on in the past. & 5.24 & 1.24 \\
\hline 8 & I feel smart when I can do something better than most other people. & 4.7 & 1.58 \\
\hline 9 & The opportunity to do challenging work is important to me. & 6.16 & 0.79 \\
\hline 10 & $\begin{array}{l}\text { When I fail to complete a difficult task, I plan to try harder the next time } \\
\text { I work on it. }\end{array}$ & 6.23 & 0.82 \\
\hline 11 & I prefer to work on tasks that force me to learn new things. & 5.55 & 1.02 \\
\hline 12 & The opportunity to learn new things is important to me. & 6.25 & 0.74 \\
\hline 13 & I do my best when I'm working on a fairly difficult task. & 5.29 & 1.26 \\
\hline 14 & I try hard to improve on my past performance. & 6.32 & 0.68 \\
\hline 15 & The opportunity to extend the range of my abilities is important to me. & 6.24 & 0.76 \\
\hline 16 & $\begin{array}{l}\text { When I have difficulty solving a problem, I enjoy trying different } \\
\text { approaches to see which one will work. }\end{array}$ & 5.84 & 1.14 \\
\hline
\end{tabular}


APPENDIX G

IPIP Scale

\begin{tabular}{|c|c|c|}
\hline Item & Mean & $\begin{array}{l}\text { Standard } \\
\text { Deviation }\end{array}$ \\
\hline 1 Am the life of the party & 2.79 & 1.03 \\
\hline 2 Feel comfortable around people. & 4.23 & .78 \\
\hline 3 Start conversations. & 3.90 & .99 \\
\hline 4 Talk to a lot of different people at parties. & 3.41 & 1.20 \\
\hline 5 Don't mind being the center of attention. & 3.18 & 1.16 \\
\hline 6 Don't talk a lot. & 3.33 & 1.19 \\
\hline 7 Keep in the background. & 3.44 & 1.03 \\
\hline 8 Have little to say. & 3.73 & .95 \\
\hline 9 Don't like to draw attention to myself. & 2.88 & 1.07 \\
\hline 10 Am quiet around strangers. & 2.88 & 1.27 \\
\hline $11 \mathrm{Am}$ interested in people. & 3.99 & .77 \\
\hline 12 Sympathize with others' feelings. & 4.08 & .77 \\
\hline 13 Have a soft heart. & 3.74 & .93 \\
\hline 14 Take time out for others. & 4.06 & .74 \\
\hline 15 Feel others' emotions. & 3.73 & .83 \\
\hline 16 Make people feel at ease. & 3.92 & .79 \\
\hline 17 Am not really interested in others. & 4.17 & .80 \\
\hline 18 Insult people. & 4.29 & .99 \\
\hline 19 Am not interested in other people's problems & 3.87 & .99 \\
\hline 20 Feel little concern for others & 4.28 & .78 \\
\hline 21 Am always prepared. & 3.79 & .83 \\
\hline 22 Pay attention to details. & 4.19 & .70 \\
\hline 23 Get chores done right away. & 3.81 & .99 \\
\hline 24 Like order. & 4.41 & .69 \\
\hline 25 Follow a schedule. & 4.10 & .84 \\
\hline
\end{tabular}




\begin{tabular}{|c|c|c|}
\hline Item & Mean & $\begin{array}{l}\text { Standard } \\
\text { Deviation }\end{array}$ \\
\hline 26 Am exacting in my work. & 4.12 & .75 \\
\hline 27 Leave my belongings around. & 3.89 & 1.04 \\
\hline 28 Make a mess of things. & 4.41 & .81 \\
\hline 29 Often forget to put things back in their proper place. & 4.20 & .90 \\
\hline 30 Shirk my duties. & 4.60 & .69 \\
\hline $31 \mathrm{Am}$ relaxed most of the time. & 3.61 & .92 \\
\hline 32 Seldom feel blue. & 3.65 & .91 \\
\hline 33 Get stressed out easily. & 3.78 & .97 \\
\hline 34 Worry about things. & 2.93 & 1.08 \\
\hline 35 Am easily disturbed. & 3.84 & .87 \\
\hline 36 Get upset easily. & 3.88 & 1.01 \\
\hline 37 Change my mood a lot. & 3.96 & 1.01 \\
\hline 38 Have frequent mood swings. & 4.26 & .96 \\
\hline 39 Get irritated easily & 4.03 & 1.06 \\
\hline 40 Often feel blue & 4.34 & .85 \\
\hline 41 Have a rich vocabulary. & 3.50 & .87 \\
\hline 42 Have a vivid imagination. & 3.70 & .86 \\
\hline 43 Have excellent ideas. & 3.94 & .65 \\
\hline 44 Am quick to understand things. & 4.01 & .67 \\
\hline 45 Use difficult words. & 2.79 & 1.01 \\
\hline 46 Spend time reflecting on things. & 3.67 & .87 \\
\hline 47 Am full of ideas. & 3.91 & .71 \\
\hline 48 Have difficulty understanding abstract ideas & 3.7 & .83 \\
\hline $49 \mathrm{Am}$ not interested in abstract ideas & 3.47 & .88 \\
\hline 50 Do not have a good imagination. & 4.08 & .93 \\
\hline
\end{tabular}


VITA

JAMES J. CONNOLLY

EDUCATION: MASTER OF SCIENCE (APRIL 1998)

FLORIDA INTERNATIONAL UNIVERSITY: MIAMI, FLORIDA

MAJOR: INDUSTRIAL/ORGANIZATIONAL PSYCHOLOGY

BACHELOR OF ARTS (JUNE 1991)

UNIVERSITY OF MIAMI: CORAL GABLES, FLORIDA

MAJOR: FINANCE

UNITED STATES NAVAL ACADEMY, ANNAPOLIS, MARYLAND

1987- 1990, HONORABLE DISCHARGE 1990

EXPERIENCE:

AON MANAGEMENT CONSULTING

CONSULTANT: 4/01 - PRESENT

SELECTION SYSTEM DESIGN, COMPETENCY MODELING, CAREER

SELECTION PLANNING AND DEVLOPMENT SYSTEMS, VALIDATION OF

SYSTEMS, JOB ANALYSIS, STRUCTURED INTERVIEWS.

MIAMI-DADE COMMUNITY COLLEGE, SCHOOL OF JUSTICE

ASSESSMENT CENTER: PROGRAM MANAGER: 2/99 - 3/01.

DEVELOPED JOB ANALYSES, JOB PROFILES, WRITTEN EXAMS.

ASSESSMENT CENTER EXERCISES (STRUCTURED INTERVIEWS, INBASKET AND INTERACTIVE EXERCISES) FOR LAW ENFORCEMENT ORGANIZATIONS. ALSO TRAINED ASSESSORS AND

ADMINSTERED ALL ASPECTS OF THE ASSESSMENT CENTER PROCESS.

THE HOME DEPOT:

INTERN - SELECTION \& MANAGEMENT DEVELOPMENT TEAMS: 08/98 $0 \longdiv { 1 / 9 9 }$

JOB ANALYSES, JOB OBSERVATIONS/INTERVIEWS, COMPETENCY MODELING, JOB PERFORMANCE FEEDBACK PROVIDER, FOCUS GROUP SME MODERATOR, DEVELOPED JOB PROFILES, PERFORMANCE REVIEWS, STRUCTRED INTERVIEW GUIDES, AND JOB ANALYSES QUESTIONNAIRES; SUCCESSION PLANNING, DEVELOPED NEW 360 SURVEY ITEMS.

FLORIDA INTERNATIONAL UNIVERSITY:

GRADUATE TEACHING ASSISTANT \& ACADEMIC ADVISOR:

$1996-1998$

AUTOMATIC DATA PROCESSING, INC. (ADP):

ACCOUNT EXECUTIVE: 1995 - 1996

RESPONSIBLE FOR NEW CLIENT TECHNICAL CONVERSIONS ONTO ADP's HUMAN RESOURCE SYSTEM, IN A CONSULTING ROLE, AT THE CLIENT SITE.

ACCOUNT MANAGER: 1993 - 1995

PROVIDED TECHNICAL SUPPORT FOR EXISTING ADP CLIENTS IN ALL HUMAN RESOURCE AREAS 
GOLD COAST PAGING, INC.:

CONTROLLER: $1991-1992$

RESPONSIBLE FOR ALL ASPECTS OF ACCOUNTING AND FINANCE

PUBLICATIONS: CONNOLLY, J. J., \& VISWESVARAN, C. (2000). THE ROLE OF AFFECTIVITY

IN JOB SATISFACTION: A META-ANALYSIS. JOURNAL OF PERSONALITY AND INDIVIDUAL DIFFERENCES, 29(2), 265-281.

CONFERENCE

PRESENTATIONS:

CONNOLLY, J. J., \& VISWESVARAN, C. (1998). AFFECTIVITY AND JOB SATISFACTION: A META-ANALYSIS. PAPER PRESENTED AT THE THIRTEENTH ANNUAL CONFERENCE OF THE SOCIETY FOR INDUSTRIAL AND ORGANIZATIONAL PSYCHOLOGY, DALLAS, TX.

CONNOLLY, J. J., \& VISWESVARAN, C. (1998). THE CONVERGENT VALIDITY BETWEEN SELF AND OBSERVER RATINGS OF PERSONALITY: A META-ANALYSIS. PAPER PRESENTED AT THE THIRTEENTH ANNUAL CONFERENCE OF THE SOCIETY FOR INDUSTRIAL AND ORGANIZATIONAL PSYCHOLOGY, DALLAS, TX.

CONNOLLY, J. J., \& VISWESVARAN, C. (1999). POSITIVE AND NEGATIVE AFFECT: A META-ANALYSIS. PAPER PRESENTED AT THE FOURTEENTH ANNUAL CONFERENCE OF THE SOCIETY FOR INDUSTRIAL AND ORGANIZATIONAL PSYCHOLOGY, ATLANTA, GA. 